\title{
¿QUÉ HUBIERA PASADO SI...? ENSEÑANZA DE LA HISTORIA Y REFLEXIÓN CONTRAFÁCTICA EN LOS CURRÍCULOS NORUEGOS DEL SIGLO XXI
}

\author{
What if...? History Education and Counterfactual Thinking \\ in the $21^{\text {th }}$ Century Norwegian Curricula
}

\author{
Julián Pelegrín Campo \\ jpelegri@unizar.es \\ Universidad de Zaragoza. España \\ Fecha de recepción: 01/04/2021 \\ Fecha de aceptación: 26/05/2021
}

Resumen: El presente trabajo se propone mostrar un panorama actualizado de la enseñanza de la historia en Noruega durante la transición entre el currículo implantado en 2006 y la nueva reforma de 2020 y analizar en particular las consecuencias del reconocimiento oficial otorgado a la utilidad didáctica de la reflexión contrafáctica en el aula como resultado de su incorporación desde 2006 entre los objetivos competenciales de las enseñanzas de la materia de historia en el sistema educativo de este país tanto durante la enseñanza obligatoria como durante la educación secundaria superior.

Palabras clave: Noruega; currículo de historia; enseñanza de la historia; historia contrafáctica.

Abstract: This paper aims to show the current state of history teaching in Norway during the transition between the curriculum implemented in 2006 and the new 2020 educational reform, and to analyze specifically the results of the official recognition granted to the didactic utility of counterfactual reflection in the classroom as a result of its incorporation since 2006 among the competence objectives of the teaching history in the educational system of this country both during compulsory education and in upper secondary education.

Keywords: Norway; history curriculum; history instruction; counterfactual history. 
SUMARIO: 1. Introducción. 2. El sistema educativo noruego en la actualidad: una etapa de transición. 3. La historia en el sistema educativo noruego: asignaturas, competencias y contenidos. 4. La reflexión contrafáctica como herramienta didáctica en el aula de historia. 5. La historia contrafáctica en el currículo noruego. 6 . La reflexión contrafáctica en los libros de texto noruegos de ciencias sociales y de historia. 7. Conclusión. 8. Referencias bibliográficas.

\section{INTRODUCCIÓN}

El principio básico del sistema educativo noruego se resume en la fórmula genérica «Educación para todos». Pero si descendemos a la realidad concreta del aula, enseguida se hace necesario plantear la cuestión del papel que debe desempeñar la enseñanza de la historia a comienzos del siglo XXI y, directamente asociada con ella, la de definir qué historia debe ser enseñada en una sociedad multicultural enfrentada a una serie de retos en el presente para los que no siempre es fácil encontrar solución mirando hacia el pasado. En un momento de transición, la nueva reforma del sistema educativo noruego se propone en la actualidad dotar al alumnado de las herramientas necesarias para afrontar esos desafíos, un objetivo para cuya consecución cabe preguntarse cuál será el protagonismo otorgado a la enseñanza de la historia.

\section{EL SISTEMA EDUCATIVO NORUEGO EN LA ACTUALIDAD: UNA ETAPA DE TRANSICIÓN}

Dentro del sistema educativo noruego se suceden varias etapas. La más temprana, el denominado «jardín de infancia» (Barnehage) no tiene carácter obligatorio y se ofrece para edades de entre 0 a 5 años. Desde 1997 la enseñanza obligatoria (Grunnskole) comienza el año en que el alumno cumple los seis años de edad y se extiende a lo largo de diez cursos, de los cuales los siete primeros conforman el ciclo correspondiente a la educación primaria (Barnetrinnet) y los tres restantes el de la educación secundaria básica (Ungdomstrinnet). Le sigue la educación secundaria superior (Videregående opplæring), etapa no obligatoria que incluye por una parte los programas educativos de preparación de estudios que dan acceso a la enseñanza universitaria (Studieforberedende utdanningsprogram) y por otra el correspondiente a la formación profesional (Yrkesfaglige utdanningsprogram): las dos fórmulas se hallan integradas por tres cursos conocidos comúnmente como Vg1, Vg2 y Vg3, los cuales pueden ampliarse en uno más en el caso de la formación profesional como consecuencia de la combinación de este tipo de enseñanzas con la realización de prácticas en empresas ${ }^{1}$.

${ }^{1}$ Vid. una aproximación básica al sistema educativo noruego en la página correspondiente de la Red europea de información en educación Eurydice (https://eacea.ec.europa.eu/national- 
Los municipios gestionan los centros de enseñanza preescolar y los de enseñanza obligatoria, mientras que los condados o provincias hacen lo propio con los de educación secundaria superior y el Kunnskapsdepartementet (Ministerio de Educación e Investigación) con las universidades y escuelas superiores. La enseñanza pública predomina, con mucho, sobre la privada y toda ella es gratuita con la excepción de la etapa preescolar, en la que los progenitores abonan una tasa en función de sus ingresos económicos y de acuerdo con la reglamentación municipal.

En el momento de escribir estas líneas el sistema educativo noruego se halla inmerso en pleno proceso de transición. Los nuevos planes de estudios de educación primaria y de educación secundaria diseñados en el marco de la reforma curricular denominada Kunnskapsløftet 2020 («Promoción del conocimiento 2020») se están implementando progresivamente a lo largo de un período de tres años, de manera que desde el inicio del año escolar 2020/2021 ya se aplican en los cursos que alcanzan desde 1. a 9. en el caso de la enseñanza obligatoria y en Vg1 en el de la educación secundaria superior, mientras que los cursos 10 . y Vg2 se incorporarán en $2021 / 22$ y finalmente Vg3 lo hará en $2022 / 2023^{2}$. En consecuencia, durante este período las diferentes etapas educativas contemplan la coexistencia de los nuevos planes con los planes anteriores, vigentes desde la instauración de la reforma Kunnskapsløftet 2006.

Tras la publicación de algunos resultados del informe PISA escasamente satisfactorios en el caso noruego, la reforma Kunnskapsløftet 2006 introdujo una perspectiva general que contemplaba de un modo unitario los trece años sumados entre la enseñanza obligatoria y la educación secundaria superior y desde la cual se propuso como objetivo fundamental adaptar el sistema educativo a las necesidades del alumnado para que este último fuese capaz de desarrollar las competencias necesarias que le permitieran participar activamente en la sociedad. Para ello integró las destrezas básicas -referidas a lectura, escritura, expresión oral, cálculo matemático y uso de las tecnologías digitales- en los objetivos competenciales (kompetansemål) de todas las asignaturas, los cuales dictan lo que el alumnado debe ser capaz de hacer en relación con cada una de ellas -durante la educación obligatoria al final

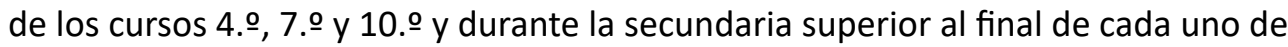

policies/eurydice/content/norway_en); estadísticas sobre la educación en Noruega con datos actualizados a comienzos del curso 2020/2021 en Statistisk Norway (https://www.ssb.no/en/ utdanning); y un glosario de la terminología educativa noruega con sus equivalencias en lengua inglesa en el Ordbok - for begreper i grunnopplæringen, norsk-engelsk/engelsk-norsk (https:// www.udir.no/verktoy/ordbok/).

2 Sobre el proceso de transición entre uno y otro currículo, vid. en la página web de la Utdanningsdirektoratet (Dirección General de Educación y Formación) dedicada a los planes de estudios la sección Innføring av nye læreplaner («Introducción de nuevos currículos»): https:// www.udir.no/laring-og-trivsel/lareplanverket/fagfornyelsen/innforing-av-nye-lareplaner/ (información actualizada a 21 de febrero de 2021). 
sus tres cursos- y se concretan en última instancia en la impartición de los contenidos asociados a las diferentes materias. Paralelamente, la reforma introdujo una estructura educativa más descentralizada, y no solo porque con ella quedase establecido un currículo independiente para la población indígena sami que garantizaba la enseñanza de su lengua y de su cultura en los niveles de educación primaria y educación secundaria, sino sobre todo porque en general se concedieron mayores competencias y responsabilidades a los centros escolares y a las autoridades locales de las que aquéllos dependen, de manera que, a pesar de ser la Utdanningsdirektoratet (Dirección General de Educación y Formación) el organismo oficial encargado desde 2004 de desarrollar el currículo y, por ello, de fijar las competencias que el alumnado debe alcanzar, sin embargo son dichas entidades locales las que, en el marco definido por aquél, han disfrutado de una amplia autonomía para decidir tanto los contenidos específicos de las asignaturas como la metodología y los materiales didácticos utilizados para impartirlos (Eurydice, 2008, p. 19; 2010, p. 31).

Tomando como base el informe presentado por el Ministerio ante el Parlamento en abril de 2016 con el objetivo de renovar los planes de estudios de todas las asignaturas y así ofrecer al alumnado un aprendizaje más adecuado, la reforma Kunnskapsløftet 2020 se propone profundizar en esa misma línea ${ }^{3}$. Los nuevos planes tampoco incluyen listas de actividades que el alumnado deba realizar ni descripciones detalladas de los conocimientos que deba asimilar, sino que continúan centrándose en describir las competencias que ese alumnado debe adquirir en cada una de las asignaturas, esto es, la combinación de conocimientos y destrezas que en adelante pueda utilizar en los diferentes escenarios que encontrará tanto en la sociedad de la que forma parte como en el contexto laboral en el que profesionalmente se va a desenvolver ${ }^{4}$. Por ello, ya desde la finalización del 2. o curso de la educación obligatoria los objetivos competenciales persiguen la implicación del alumnado en la tarea de encontrar contenidos, metodologías, recursos, escenarios, actividades y herramientas de evaluación que contribuyan a su aprendizaje. Pero, por encima de todo y en el marco diseñado precisamente por esa vinculación fundamental que se establece entre la educación por una parte y la realidad social y laboral por otra, la reforma de 2020 apunta la necesidad de abordar los desafíos

${ }^{3}$ Vid. el informe del Ministerio Fag-Fordypning - Forståelse. En fornyelse av Kunnskapsløftet («Asignaturas - Especialización - Comprensión. Renovación de Promoción del conocimiento»): https://www.regjeringen.no/no/dokumenter/meld.-st.-28-20152016/id2483955/. Sobre los principios fundamentales que animan la nueva reforma, vid. en la página web de la Utdanningsdirektoratet dedicada a los planes de estudios la sección Overordnet del - verdier og prinsipper for grunnopplæringen («Parte general: valores y principios para la educación básica»): https://www.udir.no/lk20/overordnet-del/.

${ }^{4} \mathrm{Vid}$. al respecto en la página web de la Utdanningsdirektoratet dedicada a los planes de estudios la sección Hvordan ta i bruk nye læreplaner? («¿Cómo aplicar los nuevos currículos?»): https://www.udir.no/laring-og-trivsel/lareplanverket/stotte/hvordan-ta-i-bruk-lareplanen/. 
clave de nuestro tiempo mediante la introducción de tres temas interdisciplinares en función de los cuales se articulan los nuevos planes de estudios: «salud pública y destrezas para la vida» (folkehelse og livsmestring) dotará al alumnado de una competencia que promueva en él una plena salud mental y física y que le brinde oportunidades para tomar decisiones responsables; "democracia y ciudadanía» (demokrati og medborgerskap) le permitirá conocer las condiciones previas, los valores y las reglas de la democracia, así como participar en los procesos democráticos; y "desarrollo sostenible» (bærekraftig utvikling) le concienciará de la necesidad de proteger la vida en nuestro planeta y de atender las necesidades de los seres humanos en la actualidad sin que ello implique destruir la capacidad de las generaciones futuras para satisfacer sus propias necesidades. El tratamiento de estos temas en sus diferentes aspectos resulta prioritario en todas las asignaturas del plan de estudios por cuanto contribuirá a que el alumnado identifique y comprenda las conexiones existentes tanto dentro de una misma materia como entre materias diversas que, de este modo, se revelan como complementarias entre sí5. Y una de ellas es precisamente la historia.

\section{LA HISTORIA EN EL SISTEMA EDUCATIVO NORUEGO: ASIGNATURAS, COMPETENCIAS Y CONTENIDOS}

Aunque en Noruega la enseñanza durante el Barnehage se centra fundamentalmente en el cuidado de los más pequeños y en su desarrollo a través del juego, desde la introducción del currículo correspondiente en 2017 también cuenta entre sus objetivos la promoción del aprendizaje y de la educación como base para un desarrollo integral. Y dentro del área temática «Entorno local y sociedad» (Nærmiljø og samfunn) el currículo insiste en la importancia de que el alumnado de hasta seis años se familiarice a nivel local con la historia, las tradiciones y las instituciones sociales para así poder identificarse como miembros de su comunidad y comprender que la sociedad cambia y que ellos forman parte de un contexto histórico con un pasado, un presente y un futuro ${ }^{6}$. De ahí las actividades desarrolladas en estas aulas ya con anterioridad en relación con la historia y con el patrimonio mediante el recurso a narraciones -de los docentes y de los familiares, pero también del propio alumnado- y a experiencias directas -a través de salidas escolares, manipulación de objetos, dramatizaciones, encuentros con personas mayores, degustación de la gastronomía tradicional, etc.- que

${ }^{5}$ Vid. al respecto en la página web de la Utdanningsdirektoratet dedicada a los planes de estudios la sección Hva er tverrfaglige temaer? («¿Qué son los temas interdisciplinares?»): https://www.udir.no/laring-og-trivsel/lareplanverket/stotte/hva-er-tverrfaglige-temaer/.

${ }^{6}$ Vid. al respecto en la página web de la Utdanningsdirektoratet dedicada a la enseñanza en la etapa del Barnehage la sección Nærmiljø og samfunn («Entorno local y sociedad»): https:// www.udir.no/laring-og-trivsel/rammeplan/fagomrader/narmiljo-samfunn/. 
permiten al alumnado aprender hechos históricos y adquirir un sentido básico de la cronología relativa mediante sucesiones destinadas a ubicar en el tiempo lo que se sitúa antes y lo que se sitúa después (Skjæveland, 2016 y 2017).

Por lo que se refiere a los niveles educativos que siguen a esta etapa, en un contexto caracterizado de manera transitoria por la coexistencia de los currículos de 2006 y de 2020 la estructura de la enseñanza de la historia muestra una clara continuidad en la medida en que con la introducción de los nuevos planes de estudios esta materia por una parte se mantiene integrada durante la enseñanza obligatoria en una misma asignatura junto a la geografía y una combinación de sociología y ciencias políticas bajo la denominación conjunta Samfunnsfag («Estudios sociales») como lo lleva haciendo desde 1974, mientras que por otra permanece individualizada durante la educación secundaria superior como Historie en tanto que asignatura independiente -respecto de las de Geografía (Geografi) y Estudios sociales (Samfunnsfag) ${ }^{7}$-, obligatoria y común a todas las especialidades impartidas en esta etapa. En ese sentido la estructura del plan de estudios no se ha visto afectada por la reforma aun cuando durante el presente año escolar 2020/2021 los nuevos planes ya se aplican en los cursos 1. al 9. de la enseñanza obligatoria, pero todavía no en el 10.ํ, mientras que en la secundaria superior la materia de historia continúa ausente del primer curso (Vg1, ya integrado en la reforma) y sigue siendo impartida en los otros dos (Vg2 y Vg3), si bien en estos últimos, como ya se ha apuntado, conforme al plan de estudios de 2006 hasta 2021/22 y 2022/2023 respectivamente ${ }^{8}$. En cuanto a la dotación horaria de estas materias -y siempre por detrás de las matemáticas, la lengua noruega y la lengua inglesa, consideradas prioritarias desde la reforma de 2006-, los nuevos planes de estudios adjudican un total de 634 horas a la asignatura de Samfunnsfag durante la enseñanza obligatoria, 385 de las cuales son impartidas durante la etapa correspondiente a la educación primaria (cursos 1.ㅇ - 7.ㅇ) y las 249 restantes durante la secundaria básica (cursos 8.ㅇ - 10.ㅇ) ${ }^{9}$, mientras que durante la educación secundaria superior

7 Sobre la presencia de estas otras materias en los nuevos planes de estudios, vid. Sætre (2021) y Solhaug, Borge y Grut (2020) respectivamente.

8 Sobre las fases del proceso de sustitución de los planes de estudios de 2006 por los de 2020 en la asignatura Samfunnsfag durante la enseñanza obligatoria, vid. https://www.udir.no/ Ik20/saf01-04/gyldighet-og-innfoering; en la asignatura Historie durante la secundaria superior, vid. https://www.udir.no/lk20/his01-03/gyldighet-og-innfoering.

9 Vid. al respecto en la página web de la Utdanningsdirektoratet el apartado dedicado a la educación obligatoria dentro de la sección Fag-og timefordeling og tilbudsstruktur for Kunnskapsløftet Udir-1-2020 («Distribución temática y horaria y estructura de la oferta para la Promoción del Conocimiento Udir-1-2020»): https://www.udir.no/regelverkstolkninger/ opplaring/Innhold-i-opplaringen/udir-1-2020/vedlegg-1/2.-grunnskolen/. Por otra parte, las autoridades locales que gestionan estas enseñanzas tienen la potestad de reasignar hasta el $5 \%$ de las horas de una asignatura a otra o a otras, pero siempre dentro de un mismo ciclo, esto es,

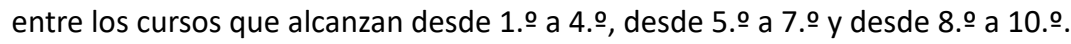


y en tanto que asignatura común a todos los programas educativos de preparación de estudios que dan acceso a la enseñanza universitaria, Historie cuenta con un total de 169 horas, 56 de las cuales son impartidas en $\operatorname{Vg} 2$ y 113 en Vg $3^{10}$.

La reforma de 2006 se había planteado como objetivo desarrollar la comprensión histórica en el alumnado ya no a través de la tradicional adquisición de conocimientos, sino mediante el desarrollo de una capacidad de reflexión que, gracias al recurso a fuentes y metodologías históricas y a la adopción de diferentes perspectivas, fomentase en aquél la conciencia histórica y el pensamiento crítico y le permitiese "saber cómo" para, de este modo, ser capaz de "saber qué», de acuerdo con el modelo educativo anglosajón (Skram, 2011; Lund, 2012; Johanson, 2015) ${ }^{11}$. Este planteamiento continúa inspirando la reforma de 2020, en la que los aspectos metodológicos de la disciplina adquieren mayor preeminencia todavía sobre el conocimiento de los hechos históricos ${ }^{12}$. Los nuevos planes de estudios persiguen que el alumnado desarrolle la conciencia histórica e identifique conexiones con el pasado contemplándolo desde diferentes perspectivas y explorándolo mediante un tratamiento crítico de las fuentes que nos informan sobre él para, de este modo, ser conscientes de que ellos mismos son resultado de la historia y, a la vez, generadores de la historia y, en consecuencia, reconocer la relevancia del pasado para el presente y para el futuro ${ }^{13}$. Precisamente en este último punto reside la asociación fundamental entre la materia de historia y los tres temas interdisciplinares ya

$10 \mathrm{Vid}$. al respecto en la página web de la Utdanningsdirektoratet el apartado dedicado a la educación secundaria superior dentro de la sección Fag-og timefordeling og tilbudsstruktur for Kunnskapsløftet Udir-1-2020 («Distribución temática y horaria y estructura de la oferta para la Promoción del Conocimiento Udir-1-2020»): https://www.udir.no/regelverkstolkninger/ opplaring/Innhold-i-opplaringen/udir-1-2020/vedlegg-1/3vgo/. La reforma de 2020 ofrece cinco programas de educación para la preparación de estudios (Studieforberedende utdanningsprogram): especialización de estudios (studiespesialisering), asignaturas deportivas (idrettsfag), música, danza y teatro (musikk, dans og drama), arte, diseño y arquitectura (kunst, design og arkitektur) y medios y comunicación (medier og kommunikasjon). Por el contrario, los estudios de formación profesional (Yrkesfaglige) no incluyen la asignatura Historie en ninguno de sus cursos, pero sí lo hace el curso complementario que, a modo de curso puente, desde ellos da acceso a los estudios universitarios (Påbygging til generell studiekompetanse), con 140 horas dentro del plan de estudios general y 113 en el plan correspondiente al currículo sami.

${ }^{11}$ En la página web de la Utdanningsdirektoratet pueden ser consultados los planes de estudios fijados por Kunnskapsløftet 2006 para las asignaturas Samfunnsfag (SAF1 03: https:// www.udir.no/kI06/SAF1-03) e Historie (HIS1-02: https://www.udir.no/kI06/HIS1-02).

12 Vid. al respecto en la página web de la Utdanningsdirektoratet la sección Hva er nytt $i$ historie? («¿Qué hay de nuevo en historia?»): https://www.udir.no/laring-og-trivsel/ lareplanverket/fagspesifikk-stotte/nytt-i-fagene/hva-er-nytt-i-historie/.

13 En la página web de la Utdanningsdirektoratet pueden ser consultados los planes de estudios fijados por Kunnskapsløftet 2020 para las asignaturas Samfunnsfag (SAF01 04: https:// www.udir.no/lk20/saf01-04) e Historie (HIS01-03 = https://www.udir.no/lk20/his01-03). 
mencionados que vertebran los nuevos planes de estudios. Durante la enseñanza obligatoria la asignatura Samfunnsfag contempla cómo dicha disciplina se diluye en el marco proporcionado por las ciencias sociales a través de las vinculaciones establecidas entre el tema "salud pública y destrezas para la vida» y la identidad del individuo en el marco de las diferentes comunidades en las que se desenvuelve; entre el tema "democracia y ciudadanía» y la participación en procesos democráticos; y, finalmente, entre el tema "desarrollo sostenible» y las consecuencias de la relación entre naturaleza y sociedad. Pero durante la educación secundaria superior la asignatura Historie insiste de manera explícita en propiciar en el alumnado 1) el descubrimiento de la conexión existente entre pasado, presente y futuro y 2) la reflexión crítica acerca de la misma y del papel protagonista que en ella desempeñan tanto el propio alumnado como la sociedad en la que vive en tanto que sujetos pacientes y agentes de la historia ("historieskapt og historieskapende», lit. «creados por la historia y creadores de historia»), y lo mismo para desarrollar el respeto por los demás y para tomar decisiones de vida responsables en relación con el primero de los temas interdisciplinares, que para reconocer la diversidad de puntos de vista, prioridades, actitudes y valores en función de los diferentes contextos y asumir su responsabilidad para desempeñarse como ciudadanos activos a propósito del segundo, y finalmente para comprender que las consecuencias de sus propias decisiones modelarán la historia de otros en el futuro y, de este modo, ser conscientes de sus propias oportunidades para contribuir a una sociedad más sostenible en el caso del tercero ${ }^{14}$. En suma, y tal como se ha apuntado recientemente, desde la perspectiva de Kunnskapsløftet 2020 el objetivo de la enseñanza de la historia

es mucho más que transmitir hechos sobre el pasado. Se trata también de educación e identidad, de ciudadanía activa, pensamiento crítico y pensamiento científico, curiosidad, exploración y compromiso, diversidad de perspectivas, valores democráticos y derechos humanos, empatía histórica, preparación para la vida laboral, conciencia ética y resolución de conflictos ${ }^{15}$.

${ }^{14}$ Sobre la presencia de los tres temas transversales en la asignatura Samfunnsfag durante la enseñanza obligatoria y en la asignatura Historie durante la secundaria superior, vid. en la página web de la Utdanningsdirektoratet los apartados Samfunnsfag (SAF01-04) - Tverrfaglege tema (https://www.udir.no/lk20/saf01-04/om-faget/tverrfaglige-temaer) e Historie (HISO103) - Tverrfaglege tema (https://www.udir.no/lk20/his01-03/om-faget/tverrfaglige-temaer) respectivamente.

15 Moum (2020): «Historiefagets mål er langt mer enn å formidle fakta om fortiden. Den handler også om dannelse og identitet, om aktivt medborgerskap, kritisk tenkning og vitenskapelig tenkemåte, nysgjerrighet, utforskning og engasjement, perspektivmangfold, demokratiske verdier og menneskerettigheter, historisk empati, forberedelse til arbeidslivet, etisk bevissthet og konfliktløsning». 
Paralelamente, esa conexión entre la materia de historia y los tres temas interdisciplinares preside los objetivos competenciales recogidos en relación con cada una de las asignaturas del plan de estudios durante la educación obligatoria al final

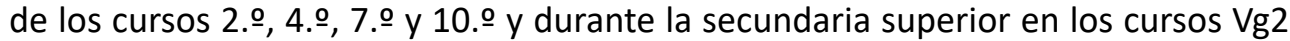
y Vg3. Tanto en una etapa como en otra la reforma de 2020 ha reducido notablemente el número de estos objetivos respecto de los definidos por la de 2006, los cuales además ya no se agrupan en áreas principales (hovudområde) como se dispuso hace tres lustros ${ }^{16}$, sino que figuran recogidos exclusivamente como una simple enumeración precedida de la consabida fórmula «El objetivo de la formación es que el alumno sea capaz de...» («Mål for opplæringa er at eleven skal kunne...») ${ }^{17}$. De igual modo, si ya con Kunnskapsløftet 2006 se había renunciado definitivamente a la adquisición de una perspectiva global de la evolución histórica fundada exclusivamente en conocimientos puramente fácticos, las referencias explícitas ya no solo a indicaciones cronológicas concretas bajo la forma de fechas, sino incluso a los períodos históricos tradicionalmente establecidos que encontrábamos entre los objetivos competenciales recogidos por esa reforma de 2006 dentro del área principal Historie ("Historia») de la asignatura Samfunnsfag durante la enseñanza obligatoria -la Prehistoria, la Edad del Bronce y la Edad del Hierro entre los exigidos al final del 4. curso; la época vikinga en Noruega, la Antigüedad grecorromana, la Edad Media, el Renacimiento y la Ilustración al final del 7.o; y la Revolución Industrial, la Revolución Francesa, el colonialismo, el imperialismo y la descolonización al final

16 Sobre los objetivos competenciales fijados por la reforma de 2006 para la asignatura Samfunnsfag al final de los cursos 4.ㅇ, 7. y 10. y para la asignatura Historie al final de los cursos Vg2 y Vg3 en función de sus respectivas áreas principales -Utforskaren («Explorador», de carácter metodológico y centrada en potenciar la reflexión crítica mediante el uso de fuentes de información), Historie («Historia»), Geografi («Geografía») y Samfunnskunnskap («Estudios sociales») en caso de la primera; Historieforståelse og metoder («Entender la historia y los métodos») y Samfunn og mennesker $i$ tid ("Sociedad y seres humanos en el tiempo») en el de la segunda-, vid. respectivamente las secciones Læreplan i samfunnsfag (SAF1-03) - Kompetansemål («Currículo de ciencias sociales [SAF1-03] - Objetivos competenciales»: https://www.udir.no/kl06/SAF1-03/Hele/Kompetansemaal) y Læreplan i historie - fellesfag i studieforberedende utdanningsprogram (HIS1-02) - Kompetansemål ("Currículo de historia: materias comunes en el programa de educación de preparación de estudios [HIS1-02] objetivos competenciales»: https://www.udir.no/kl06/HIS1-02/Hele/Kompetansemaal); sobre esas mismas áreas principales, vid. para cada asignatura Læreplan i samfunnsfag (SAF1-03) Hovudområde (https://www.udir.no/kl06/SAF1-03/Hele/Hovedomraader) y Læreplan i historie fellesfag i studieforberedende utdanningsprogram (HIS1-02) - Hovudområde (https://www.udir. no/kI06/HIS1-02/Hele/Hovedomraader) respectivamente.

17 Vid. los objetivos competenciales fijados por la reforma de 2020 para la asignatura Samfunnsfag al final de los cursos 2.ㅇ, 4.ㅇ, 7.․ y 10. y para la asignatura Historie al final de los cursos Vg2 y Vg3 en las correspondientes secciones homónimas Kompetansemål og vurdering («Objetivos competenciales y evaluación») https://www.udir.no/lk20/saf01-04 y https://www. udir.no/lk20/his01-03 respectivamente. 
del 10.- ahora han desaparecido del listado general de objetivos competenciales fijados por Kunnskapsløftet 2020 para esa misma asignatura, sustituidas por alusiones temporales de carácter genérico -así "la época de origen» y "antes y ahora» una vez finalizado 4.ㅇ; "el pasado" y "eventos clave» tras 7.--, con la única excepción de fenómenos históricos de especial importancia por su significación en tanto que atentado contra los derechos humanos, como sucede a nivel universal con el Holocausto -evocado de manera explícita a propósito del análisis de las causas y consecuencias de actos terroristas y genocidios y la consiguiente reflexión sobre cómo prevenirlos- y en el ámbito local con el proceso de «norueguización» impuesto en el pasado a la población indígena sami. Lo mismo se observa en relación con la presentación de diferentes fenómenos históricos bajo la fórmula genérica «encuentros entre personas", la cual no hace sino homogeneizarlos desde una perspectiva presentista que amenaza con despojarlos de su carácter histórico en tanto que propios de momentos y contextos determinados. Aun sin llegar a tales extremos, un fenómeno similar se advierte en la enseñanza secundaria superior, pues la simple mención de la Edad Media entre los objetivos competenciales que deberían haberse alcanzado una vez finalizado el curso Vg2 y de la llustración y las Guerras Mundiales entre los fijados tras la finalización de Vg3 tal como lo establece la reforma de 2020, no llega a ocultar la desaparición de menciones explícitas a otros referentes históricos fundamentales como las sociedades primitivas, las sociedades antiguas o la expansión europea en relación con Vg2 y a la Revolución Industrial y el colonialismo en relación con Vg3 tal como figuraban dentro del área principal Samfunn og mennesker i tid («Sociedad y seres humanos en el tiempo») de la asignatura Historie conforme a la reforma de 2006.

Ese tratamiento genérico y esa falta de concreción de los contenidos evidenciados de manera consciente por el plan de estudios ofrecen a las autoridades escolares locales, a los docentes y al propio alumnado la posibilidad de seleccionar cuáles de esos contenidos serán abordados dentro de las asignaturas de historia incluidas en los planes de estudios y cómo serán impartidos en el aula. Pero también alimenta la oferta de materiales curriculares por parte de las editoriales en la medida en que, al tratarse de una herramienta de uso en el aula, constituye de hecho la plasmación sobre el terreno de lo dictado por los objetivos competenciales, y con mayor razón dados por una parte el margen concedido tras la derogación en junio de 2000 del sistema estatal de aprobación de los libros de texto escolares precisamente ante la necesidad de otorgar al profesorado una libertad de elección y una responsabilidad mayores en la planificación de su docencia (Bratholm, 2001) y por otra la primacía que, a pesar de ello, el libro de texto continúa evidenciando en las aulas de historia como herramienta didáctica básica (Justvik, 2012 y 2014). Y en este punto resulta significativa la comparación entre los manuales editados conforme a los principios dictados por Kunnskapsløftet 2006 y los que en la actualidad están siendo publicados de acuerdo con Kunnskapsløftet 2020. 
Por lo que se refiere al primer grupo, durante los cursos iniciales de la enseñanza obligatoria los contenidos históricos, geográficos y relativos a las ciencias sociales que conforman la asignatura Samfunnsfag figuraban englobados en los libros de texto junto con los contenidos de ciencias naturales bajo la fórmula Naturfag og samfunnsfag ("Naturaleza y sociedad») y a partir de 5. curso aparecían ya individualizados como Samfunnsfag ("Sociedad»). Generalmente durante el primer curso la asignatura Samfunnsfag ha transmitido al alumnado una aproximación elemental al paso del tiempo mediante la comparación de su contexto escolar con el de sus progenitores y el de sus abuelos, mientras que los siguientes cursos planteaban sucesivamente y por orden cronológico una aproximación básica a la historia de Noruega en particular en el marco de la historia universal en general desde la Edad de Piedra en 2. curso, la Edad del Bronce en 3. y la Edad del Hierro en 4. para, a continuación, abordar la historia universal hasta el fin del mundo antiguo en 5. o curso y profundizar en los ámbitos universal y local básicamente durante la Edad Media en 6.․, la Edad Moderna en 7.ㅇ, la segunda mitad del siglo XVIII y todo el

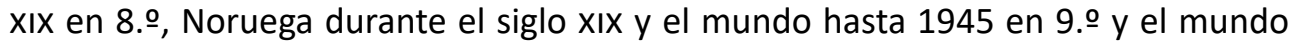
desde 1945 hasta la actualidad en 10. curso $^{18}$. Por el contrario, entre los manuales escolares editados conforme a la reforma de 2020 a los que hemos tenido acceso encontramos la asignatura Samfunnsfag individualizada e independiente de las ciencias naturales ya desde los primeros cursos en los volúmenes Arena 1-2. Samfunnsfag y Samfunnsfag 1+2 fra Cappelen Damm editados por Aschehoug y Cappelen Damm respectivamente ${ }^{19}$, si bien las dos áreas siguen figurando asociadas en todos los manuales de los cursos 1. a 4. de la serie Refleks editada por Gyldendal $(2020-2021)^{20}$. Paralelamente, en ninguna de estas series encontramos la consabida aproximación básica al aprendizaje del tiempo mediante la formulación explícita de cuestiones tales como "¿cómo era ser niño en el pasado?», "¿cómo era antes la escuela?» o "¿cómo y por qué los lugares cambian?» hasta el 2. curso con los temas Hvordan var det før? («¿Cómo era antes?») en el volumen correspondiente

18 En términos generales así lo han hecho editoriales como Aschehoug con sus series Cumulus para 1.--4. (2006-2008) y Midgard para 5.--7.ㅇ (2006-2008), Cappelen Damm con Mylder para los cursos 1.-.4. (2013-2016) y Globus para 5.--7.o (2006-2008) y Fagbokforlaget con Kosmos para 8.ํ, 9. y 10. (2006-2007), si bien en ocasiones la oferta se amplía con ediciones de manuales escolares individualizados para las áreas de Historia, Geografía y Estudios sociales de la misma asignatura durante un mismo curso, como ha hecho Cappelen Damm en sus series Makt og Menneske (2006-2008) y Nye Makt og Menneske (2014-2016) para los cursos 8.․, 9. y 10 .‥

19 S. A. Eie y T. Lien (2020). Arena 1-2. Samfunnsfag. Oslo: Aschehoug; A. Klepp, M. H. Sandberg, A. S. Steinset y H. M. Stoltenberg (2020). Samfunnsfag 1+2 fra Cappelen Damm. Oslo: Cappelen Damm.

20 Vid. en la página web de la editorial la sección dedicada a esta serie: https://www. gyldendal.no/soek/?q=refleks. 
de Arena $^{21}$, Livet før og nå ("La vida antes y ahora») en el de Cappelen Damm ${ }^{22}$ y Barn før og nå («Niños antes y ahora») en el de Refleks ${ }^{23}$. Pero en este último ya se introducen apuntes históricos y referencias cronológicas básicas a propósito de la emigración noruega a Norteamérica y tras la Segunda Guerra Mundial en el tema dedicado al pasado de Noruega -mediante las fórmulas "For over 100 år siden" («Hace más de 100 años») en el primer caso y «For 80 år siden» («Hace 80 años») en el segundo ${ }^{24}-\mathrm{y}$ a la prehistoria en ese mismo tema y en el dedicado a la evolución tecnológica -con "For 11.000 år siden» ("Hace más de 11.000 años») y "For lenge, lenge siden» («Hace mucho, mucho tiempo») respectivamente ${ }^{25}$-, mientras que en esa misma serie la época vikinga figura por extenso durante el curso 3.0 bajo el título $\AA$ utforske fortida («Para explorar el pasado») ${ }^{26}$, pero lo hace durante el 5.o curso en el de la serie Arena con Spor etter vikingtid («Huellas de época vikinga»)27. Pero si en ese mismo 5. curso el manual Samfunnsfag 5 fra Cappelen Damm cita a Hitler y el nazismo es para establecer un paralelismo entre la ocupación alemana de Noruega y la huida de los judíos noruegos durante la Segunda Guerra Mundial por una parte y el conflicto de Siria y el consiguiente problema de los refugiados en la actualidad por otra en el tema 4 Røtter i flere land («Raíces en varios países») ${ }^{28}$, del mismo modo que en el ya citado volumen de la serie Refleks dedicado a 3.ㅇ se alude a la Revolución Francesa exclusivamente en relación con el origen del reconocimiento de los derechos humanos en el tema 5 Menneskerettigheter («Derechos humanos» $)^{29}$. Y los volúmenes destinados a 8.ㅇ curso editados en 2020 por Gyldendal y por Cappelen Damm abordan la historia del siglo XIX presentando acontecimientos y fenómenos históricos como la llustración, la Revolución Americana, la Revolución Francesa, la Revolución Industrial, el imperialismo, el nacionalismo y el colonialismo no mediante esa tradicional terminología historiográfica de carácter

${ }^{21}$ Eie y Lien (2020), op. cit. n. 19, pp. 64-83.

22 Steinset y Stoltenberg (2020), op. cit. n. 19, pp. 76-91.

${ }^{23}$ O. Bjerknes, T. G. Lie e Y. Skjæveland (2020). Refleks 2. Naturfag og Samfunnsfag. Oslo: Gyldendal, pp. 98-113.

24 Ibid., tema 4 Hvem er vi? («¿Quiénes somos?»), apartado Fra Norge til andre land («De Noruega a otros países»), p. 81.

${ }_{25}$ Ibid., tema 4, p. 67; tema 5 Teknologi («Tecnología»), apartado Hva er teknologi? («¿Qué es la tecnología»), p. 87.

26 N. A. Fossum, T. G. Lie, E. Lyngvær e Y. Skjæveland (2021). Refleks 3. Naturfag og Samfunnsfag. Oslo: Gyldendal, pp. 80-103.

${ }^{27}$ K. Gregers Eriksen, S. Kristensen Grødem, T. Skjelbred Nodeland y G. Sibeko (2020). Arena 5. Samfunnsfag. Oslo: Aschehoug, pp. 22-59.

${ }^{28}$ M. Bjerkaas, H. Bones, K. Veel Krauss y $\emptyset$. Stenersen (2021). Samfunnsfag 5 fra Cappelen Damm. Oslo: Cappelen Damm, pp. 4-35.

${ }^{29}$ Fossum et al. (2021), op. cit. n. 26, pp. 122-143. 
fáctico, sino bajo fórmulas que los asocian con cuestiones relevantes de actualidad como la lucha por los derechos, la construcción de la democracia, la evolución tecnológica o la guerra ${ }^{30}$.

En cuanto a los libros de texto de educación secundaria superior, tanto los publicados de acuerdo con la reforma de 2006 como los editados posteriormente conforme a la de 2020 coinciden en abarcar un marco cronológico correspondiente a la historia universal en el que se concede un tratamiento muy somero a la prehistoria y al mundo antiguo, algo más extenso a las épocas medieval y moderna -contenidos todos ellos impartidos durante el curso Vg2- y centrado fundamentalmente en la época contemporánea -cuyos contenidos ocupan todo el curso Vg3-. Sin embargo, llama la atención el hecho de que a partir de la revisión parcial del currículo de 2006 llevada a cabo en 2013 las nuevas ediciones dedican una especial atención y, en consecuencia, un espacio individualizado tanto a la cuestión de la finalidad de la historia como a la incorporación de aproximaciones novedosas a su enseñanza en el aula. Así, en el volumen Perspektiver. Historie Vg2-Vg3 publicado por Gyldendal (2013) el bloque Historie dedicado a la exposición por orden cronológico de los contenidos ocupa el segundo lugar, por detrás de una introducción destinada a explicar qué es la historia y por qué estudiarla (Framgangsmåter [«Procedimientos»], pp. 9-22) y antes de un tercer bloque centrado en cuestiones de carácter metodológico (Kurs [«Curso»], pp. 539-556) y, lo más interesante, del cuarto y último, el cual, bajo el título Essay («Ensayo», pp. 557-599), reúne diez textos redactados por historiadores y escritores noruegos interesados en la historia que pueden ser utilizados por el alumnado para profundizar en el tema allí tratado a partir de una serie de actividades propuestas al final de cada uno ${ }^{31}$. En 2016 Aschehoug edita I ettertid. Lærebok i historie for vg2 og vg3, un volumen integrado por una introducción acerca de la utilidad de la historia (Se verden i 4D! [«iVea el mundo en 4D!»], pp. 6-15) a la que siguen 25 temas articulados cada uno de ellos en función de una serie de textos centrados en personajes, acontecimientos y fenómenos históricos relacionados con el tema en cuestión, desde la Atenas de Pericles en Verdens første demokrati ("La primera democracia del mundo») hasta el mundo actual en Ekstrem islamisme («Islamismo extremo») y el caso de la localidad noruega de Stord como

${ }^{30}$ V. Heidenreich y M. J. Moe (2020). Relevans 8. Samfunnsfag. Oslo: Gyldendal; L. Bredahl, E. Dehle, S. Hammer, R. G. Hansen, S. Kuraas Karlsen, V. Kaasen Krogsrud, A. Mokhtari, E. Mæhlumshagen, M. Samuelsen y B. Stenvik (2020). Samfunnsfag 8 fra Cappelen Damm. Oslo: Cappelen Damm.

31 P. A. Madsen, I. Killerud, H. Roaldset, A. B. Hansen y E. Sæther (2013). Perspektiver. Historie Vg2-Vg3. Oslo: Gyldendal. Englobadas en la sección Gjøre («Tareas»), dichas cuestiones figuran además en sendas hojas de trabajo en formato Word dentro de un banco de recursos (Perspektiver Ressursbank) accesible en la página web de la editorial que incluye asimismo imágenes, mapas y vídeos relacionados con los contenidos del manual: https://podium. gyldendal.no/perspektiver/elev/ressursbank-elev. 
ejemplo de evolución histórica durante los últimos cinco siglos en Den lange historien ("La larga historia») ${ }^{32}$. Y en fechas muy recientes afortunadamente ya hemos podido consultar el volumen Alle tiders Historie. Fra de eldste tider til våre dager, editado por Cappelen Damm en 2020 de acuerdo con los principios de la nueva reforma $-y$, en consecuencia, destinado a su utilización en Vg2 a partir del curso 2021/2022 y en Vg3 a partir del siguiente-, que por una parte incluye un capítulo inicial de carácter metodológico en el que, tras constatar el interés que el pasado despierta en las diferentes manifestaciones de la cultura popular contemporánea, se destaca la utilidad de la historia para entendernos a nosotros mismos y a los demás en el marco de un mundo globalizado a través del análisis crítico de las fuentes y del desarrollo de la conciencia histórica (Introduksjon: Historie - hva, hvorfor og hvordan? ["Introducción: Historia, ¿qué, por qué y cómo?»], pp. 11-25), mientras que por otra dedica sendos espacios específicos a la vinculación de la materia de historia con dos de los temas interdisciplinares que vertebran los nuevos planes de estudio bajo los títulos "El desarrollo sostenible en una perspectiva histórica» (Tverrfaglig tema: Bærekraftig utvikling i et historisk perspektiv) y «Democracia y ciudadanía» (Tverrfaglig tema: Demokrati og medborgerskap) ${ }^{33}$.

A pesar del escaso número de elementos de comparación con el que contamos en el caso de los libros de texto de historia destinados a la educación secundaria superior editados conforme a Kunnskapsløftet 2020 -una limitación evidente, dado que todavía no han llegado a las aulas-, podemos adelantar que las diferencias apuntadas más arriba entre los correspondientes a los cursos de la reforma de 2006 y la de 2020 dentro la enseñanza obligatoria no resultan, sin embargo, tan notables en la etapa que le sigue. Con todo, entre una y otra se observa una continuidad dentro del planteamiento general que las anima: por una parte, durante la enseñanza obligatoria se ha acentuado todavía más la integración de la historia en la asignatura Samfunnsfag en tanto que un estudio social más, el cual, dentro de una aproximación interdisciplinar junto con la geografía y las ciencias sociales, resulta planteado en todo momento en función de los desafíos relevantes del mundo actual; por otra,

${ }^{32}$ K. Dørum, S. V. Hellerud, K. Knutsen y M. Njåstad (2016). I ettertid. Lærebok i historie for Vg2 og Vg3. Oslo: Aschehoug.

33 T. Heum, K. D. Martinsen, T. Moum y O. Teige (2020). Alle tiders historie. Fra de eldste tider til våre dager. Oslo: Cappelen Damm. Cada uno de esos temas interdisciplinares se halla repartido en dos partes que se ubican tras el bloque dedicado a Vg2 (Del 1: pp. 238-243 y 244247 respectivamente) y tras el dedicado a Vg3 (Del 2: pp. 616-621 y 622-627 respectivamente). La edición anterior de este volumen, publicada en 2013 con el mismo título y conforme a la reforma de 2006, ya incluía el tema de carácter metodológico Historieforståelse og metoder («Comprensión de la historia y métodos»), de extensión mucho más reducida, pero repartido igualmente en dos partes ubicadas tras los bloques correspondientes a Vg2 y a Vg3: T. Heum, K. D. Martinsen, T. Moum y O. Teige (2013). Alle tiders historie Vg2-Vg3. Fra de eldste tider til våre dager. Oslo: Cappelen Damm, pp. 585-586 y 587-587 respectivamente. 
durante la educación secundaria superior la historia continúa recibiendo una atención específica a través de un tratamiento individualizado en tanto que disciplina independiente, pero igualmente ya no entendida como una sucesión cronológica de acontecimientos y procesos del pasado transmitidos a modo de herencia cultural con la finalidad de construir una identidad nacional, sino con un especial interés en estimular en el alumnado la adquisición de una serie de competencias y destrezas a través del manejo crítico de las informaciones disponibles y del desarrollo de la conciencia histórica (Thue, 2019).

Y precisamente en el marco dibujado por esta progresión, tanto en la primera como en la segunda de esas etapas educativas y lo mismo como resultado de la reforma de 2006 que en relación con la de 2020, es donde encontramos lo que bien puede considerarse como el elemento más original de cuantos podamos hallar entre los objetivos competenciales que definen el plan de estudios de historia en Noruega y, en consecuencia, en su plasmación en los materiales curriculares: el recurso a la reflexión contrafáctica como herramienta didáctica.

\section{LA REFLEXIÓN CONTRAFÁCTICA COMO HERRAMIENTA DIDÁCTICA EN EL AULA DE HISTORIA}

Mediante la formulación de la pregunta «¿Qué hubiera pasado si...?» en el marco de la investigación histórica, la reflexión contrafáctica permite elaborar planteamientos alternativos a episodios y procesos del pasado con la finalidad, en primer lugar, de investigar hasta qué punto un cambio históricamente verosímil en la sucesión de los acontecimientos que conforman nuestra historia podría haber modificado el devenir de la misma en una dirección diferente a aquella que ha conducido, en última instancia, hasta nuestra realidad, y en segundo lugar, en un ejercicio de ida y vuelta caracterizado por la reflexión crítica, utilizar esa «historia que no fue» para comprender mejor lo que realmente sucedió.

En publicaciones anteriores hemos analizado cómo esta fórmula -conocida como "historia contrafáctica», "historia alternativa» o "ucronía»-constituye una herramienta de especial interés y utilidad en el ámbito de la didáctica de la historia en la medida en que constituye un estímulo particularmente atractivo para el alumnado que le permite desarrollar el pensamiento crítico ${ }^{34}$. El uso del razonamiento contrafáctico con un propósito didáctico se halla documentado ya desde la Antigüedad, pues pocos años después de que el historiador romano Tito Livio se plantease

${ }^{34}$ Estados de la cuestión: Pelegrín Campo (2010) y (2014a). Análisis de experiencias y propuestas vinculadas al aula de historia mediante el recurso a materiales curriculares en Pelegrín Campo (2014b) y a manifestaciones de la cultura popular contemporánea como el falso documental en Pelegrín Campo (2013) y el cómic en Delgado-Algarra y Pelegrín Campo (2018) y en Pelegrín Campo (2018). 
"cuál hubiera sido la suerte de Roma si hubiera tenido que hacer la guerra con Alejandro» en el excurso más extenso conservado en la parte que de su Ab Vrbe condita ha llegado hasta nosotros (IX 17-19), Elio Teón de Alejandría formulaba la misma cuestión a modo de recurso didáctico explícitamente recomendado para plantear a

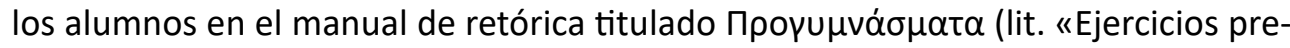
paratorios») cuando apuntaba que "es útil igualmente conjeturar el futuro a par-

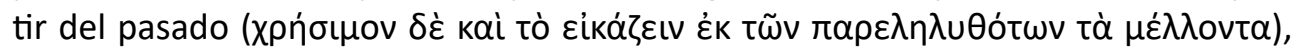
como si uno dijera acerca de Alejandro el Macedonio: “¿Qué hubiera hecho, después de someter tantos y tan grandes pueblos, si hubiera vivido aún un poco más de tiempo?"» (110, 29 ss.; Gibson, 2004, pp. 113 y 123-124). Sin embargo, habría de transcurrir mucho tiempo hasta volver a tener noticia de esa utilización didáctica de la historia contrafáctica, algo que no sucederá hasta el siglo xx y en ámbitos y formatos absolutamente ajenos a la educación formal. En primer lugar la encontramos en el cómic, pues es en las revistas infantiles norteamericanas New Comics y More Fun Comics donde entre diciembre de 1935 y octubre de 1937 encontramos veinte entregas de las secciones educativas Just suppose... e Imagine that..., las cuales, con texto y dibujo de Henry C. Kiefer y entintado de A. D. Kiefer, mostraban en dos páginas qué hubiera pasado si la existencia de ciertos personajes -Juana de Arco, Napoleón, Charles Goodyear y Abraham Lincoln entre otros- y el desarrollo de determinados acontecimientos de la historia universal-desde las Termópilas a El Álamo, pasando por la Carta Magna y la Gran Armada- hubiesen seguido derroteros diferentes a los conocidos (Kiefer y Kiefer, 1935-1936, 1936 y 1936-1937). Y años más tarde la encontramos en la radio con las trece entregas del programa Stroke of Fate, emitido semanalmente entre octubre y diciembre de 1953 por la cadena norteamericana NBC, en cada una de las cuales y a lo largo de 30 minutos se asistía en primer lugar a la dramatización de un determinado acontecimiento histórico -las conquistas de Alejandro Magno, la batalla de Hastings, la Revolución Francesa, la adquisición de Alaska por los Estados Unidos, entre otros-, seguida por la elección de un punto de divergencia -en el que tendría lugar el "golpe del destino» al que hace referencia el título de la serie-y por la dramatización de la consiguiente especulación histórica, para terminar generalmente con una explicación a cargo del historiador Allan Nevins. Llama la atención precisamente cómo esta fórmula, basada en el recurso a una narración de carácter inmersivo destinada tanto a proporcionar informaciones al oyente como a desarrollar en él una reflexión crítica, contó con el asesoramiento de historiadores vinculados a la Society of American Historians de la Universidad de Columbia -entre ellos el especialista en Antigüedad clásica Moses Hadas, pionero en el uso didáctico de la televisión-, si bien tan interesante experiencia lamentablemente pronto fue cancelada por falta de patrocinadores comerciales (Radio Nouspace, 2013-).

La cuestión fue planteada por vez primera en el marco de la educación formal a finales de la década de 1960 e igualmente en los Estados Unidos, cuando docentes 
norteamericanos insatisfechos con los métodos de enseñanza-aprendizaje tradicionales se interesaron por conocer hasta qué punto en el aula de historia es posible abordar el análisis de acontecimientos que nunca sucedieron con la finalidad de comprender mejor los que realmente sucedieron en la historia que conocemos. En este sentido, Wayne Dumas reconocía a la reconstrucción especulativa de la historia un notable potencial educativo: entre el alumnado se revelaba como un desafío «inusualmente estimulante» y le ofrecía la posibilidad de «hacer algo con la historia» a través de un proceso activo de investigación, reflexión y creación al identificar y valorar la importancia de las diferentes fuerzas que interactúan en determinado momento histórico -para lo cual el propio autor sugería varias encrucijadas en la historia de los Estados Unidos-, seleccionar una de ellas, formular a partir de ella una serie de posibilidades en términos de la relación causa-efecto y, finalmente, recrear el devenir histórico resultante de la aplicación de esa nueva perspectiva hasta alcanzar su propio presente e incluso extraer conclusiones de cara al futuro (Dumas, 1969). Estudios posteriores publicados en revistas como Teaching History, The History Teacher o History and Social Science Teacher confirmaron el especial interés que, a diferencia de los métodos didácticos tradicionales, esta fórmula despierta en el alumnado y cómo ello se traduce en términos de motivación, participación activa, actitud creativa y desarrollo de un pensamiento crítico en el marco de un proceso extremadamente dinámico en el que los estudiantes se plantean lo que pudo haber sucedido, pero no sucedió, para comprender mejor lo que realmente sucedió, y, lo más importante, por qué sucedió (Pelegrín Campo, 2010, pp. 23-28; 2014b, pp. 118-119).

Esas iniciativas particulares de los docentes fueron dando paso a un tratamiento más académico al ser incorporadas a los estudios generales sobre didáctica de la historia. Fue pionero en este sentido el capítulo "Historical Imagination» de Peter J. Lee publicado en el volumen colectivo Learning History (Dickinson, Lee y Rogers, 1984) hasta la generalización del fenómeno ya en el siglo XXI y tras la publicación a finales del anterior de sendas aportaciones fundamentales a la defensa del pensamiento contrafáctico como instrumento de reflexión histórica formuladas por Alexander Demandt y por Niall Ferguson: el primero destacó su utilidad para comprender las diferentes situaciones y el potencial que encierran de cara al futuro, juzgar las causas, sostener juicios de valor y valorar posibilidades, pues «reflexionar sobre la historia que nunca sucedió (...) encuentra su valor didáctico en el conocimiento de la historia que ha sucedido (...). Arranca de la historia real y retorna a la historia real» (Demandt, 1993, p. $2=$ Id., 2011, p. 16) ${ }^{35}$, mientras que el segundo de-

${ }^{35}$ La cita figura en las ediciones revisadas y ampliadas de la obra de Alexander Demandt Ungeschehene Geschichte. Ein Traktat über die Frage: Was wäre geschehen, wenn...? (Gotinga, 1984), la cual tiene su origen en un seminario que sobre el tema había impartido su autor durante el curso 1983/1984 en la Freie Universität de Berlín y cuya equivalencia en créditos para el alumnado matriculado en él no fue reconocida por la comisión de evaluación de dicha 
fendió el uso de este tipo de aproximación para rechazar las teorías deterministas de la historia, explorar la solidez de las construcciones históricas y valorar la importancia de la acción del individuo y del azar (Ferguson, 1998, pp. 13-85) ${ }^{36}$.

Los primeros años del siglo XXI han contemplado cómo el tratamiento de la cuestión ha evolucionado desde la descripción de experiencias de aula desarrolladas de manera aislada gracias a la iniciativa particular de determinados docentes hasta la generalización de este tipo de prácticas como consecuencia de su incorporación al mercado editorial de la enseñanza, en un primer momento mediante la formulación de propuestas basadas en el recurso a materiales preexistentes y posteriormente como resultado de la creación ex profeso de nuevos materiales tanto en el marco proporcionado por compilaciones generales de recursos pedagógicos y guías didácticas para uso del profesorado de historia, como bajo la forma de colecciones y libros de texto destinados a su alumnado (Pelegrín Campo, 2010, pp. 2935; 2014b, pp. 119-121). Desde esas fechas hasta la actualidad hemos asistido a una notable expansión del recurso a la reflexión contrafáctica en el aula de historia que se ha plasmado en la difusión de un número cada vez mayor tanto de propuestas formuladas como de experiencias ya desarrolladas en diferentes niveles educativos, sobre todo tras la publicación en 2013 de la obra de Peter Seixas y Tom Morton The Big Six Historical Thinking Concepts, pues la que en estos últimos años se ha convertido en la biblia de la didáctica de la historia incluye entre sus páginas el razonamiento contrafáctico como uno de los recursos de especial utilidad para abordar la relación causa-consecuencia y la relevancia histórica en el aula ${ }^{37}$. Y asimismo en España, donde a estudios pioneros que introdujeron la reflexión contrafáctica en el aula de historia asociándola al uso didáctico de los videojuegos (vid. los recogidos

universidad, lo cual constituye un buen ejemplo de las dificultades con las que tropezó la reivindicación de la reflexión contrafáctica en el ámbito académico (Jensen, 2005, pp. 155-156) y contrasta con su posterior reconocimiento tal como se refleja en la publicación en 2002 de la entrada "Kontrafaktische Geschichte», redactada por el mismo Demandt, entre los cien términos básicos que integran el Lexikon der Geschichtswissenschaft (2002, pp. 190-191).

36 Más recientemente la utilidad didáctica del razonamiento contrafáctico ha sido reconocida asimismo desde la perspectiva del análisis histórico por Deluermoz y Singaravélou (2016), pp. 297-310.

37 Seixas y Morton (2013), pp. 114 y 125-126. Además de la bibliografía recogida en Pelegrín Campo (2010) y (2014b), la incorporación de la reflexión contrafáctica a las publicaciones más recientes en el ámbito de la didáctica de la historia se constata en Smith (2010), Kitson, Husbands y Steward (2011), Woodcock (2011), Cooper (2013), Lévesque (2013), Rodwell (2013), Howorth (2015), Buxton (2016), Cercadillo, Chapman y Lee (2017), Clark y Nye (2018), Goldberg y Savenije (2018), Wright-Maley, Lee y Friedman (2018), Rodwell (2019) y Percival (2020). Contamos asimismo con ejemplos muy variados de su protagonismo como objeto de propuestas y de experiencias en el aula en Buxton (2010), Ferlazzo (2011), Roberts (2011), Worth (2012), Huijgen y Holthuis (2014), Maar (2014), Lieberoth (2015), Tarr (2016), Thomas (2017), Carroll (2018), Hailat, Eyadat y Zaid (2018), Simone (2018), Navey (2019), Beavers (2020) y Wendell (2020). 
en Pelegrín Campo, 2010, pp. 37-43) y algunos que lo han hecho en relación con el aprendizaje de las nociones de causalidad histórica (Feliu y Hernàndez Cardona, 2011, pp. 113-114) y de cambio y continuidad (Miralles, Molina y Ortuño, 2011, pp. 105-106), como instrumento para la educación democrática (Santisteban, 2010, pp. 48-49) o como estímulo para el alumnado con altas capacidades (López Garzón, 2012, pp. 177-178), se han sumado otros más recientes que abordan la cuestión igualmente en relación con el uso didáctico de los videojuegos (Jiménez-Palacios y Cuenca, 2015; Jiménez Alcázar y Rodríguez, 2020) y de los juegos de simulación (Frutos, 2016), pero también en el ámbito de las relaciones internacionales (Moreno, 2020) e incluso en tanto que herramienta para la evaluación del desarrollo del pensamiento histórico entre el alumnado de Educación Secundaria Obligatoria y Bachillerato (Domínguez Castillo, 2015 y 2016; Domínguez Castillo, Arias, Sánchez, Egea y García, 2016; Fuster, 2018).

En esa evolución un hito fundamental se halla representado por el reconocimiento definitivo de la utilidad didáctica de la historia contrafáctica como consecuencia de un acontecimiento clave en el tema que nos ocupa: la integración de la reflexión contrafáctica en el mismísimo currículo educativo. Un fenómeno inaugurado precisamente en el sistema educativo noruego.

\section{LA HISTORIA CONTRAFÁCTICA EN EL CURRÍCULO NORUEGO}

Ya hemos hecho referencia al protagonismo desempeñado por los objetivos competenciales tanto en Kunnskapsløftet 2006 como en Kunnskaps/øftet 2020 en la medida en que definen la combinación de conocimientos y destrezas que en adelante el alumnado podrá aplicar en los diferentes escenarios en los que se desenvuelva tanto en la sociedad de la que forma parte como en el contexto laboral en el que vaya a desarrollar su trayectoria profesional. $Y$ es precisamente entre los objetivos competenciales asociados a la impartición de la materia de historia durante la enseñanza obligatoria y durante la educación secundaria superior donde encontramos el recurso a la reflexión contrafáctica.

Tanto la reforma de 2006 como la revisión que de la misma tuvo lugar en 2009 recogían entre los objetivos competenciales del área de historia dentro de la asignatura Samfunnsfag impartida durante la enseñanza obligatoria que al finalizar el décimo y último curso de la misma el alumnado fuese capaz de

encontrar ejemplos de acontecimientos que han ayudado a dar forma a la actual Noruega y reflexionar sobre cómo la sociedad podría haber sido si estos acontecimientos se hubiesen desarrollado de un modo diferente ${ }^{38}$.

38 Samfunnsfag (SAF1-01) (2006) y Samfunnsfag (SAF1-02) (2009): «finne døme på hendingar som har vore med på å forme dagens Noreg, og reflektere over korleis samfunnet 
Paralelamente, la misma reforma establecía como uno de los objetivos competenciales de la asignatura Historie impartida durante la educación secundaria superior que al finalizar el tercer y último curso de este ciclo el alumnado fuese capaz de

encontrar ejemplos de acontecimientos que han dado forma a la historia de un país no europeo después de 1900 y reflexionar sobre cómo podría haberse desarrollado el país si estos acontecimientos no hubieran tenido lugar ${ }^{39}$.

La reforma de 2020 conserva el recurso al pensamiento contrafáctico entre los objetivos competenciales de las asignaturas de la materia de historia, si bien formulado en unos nuevos términos. En el caso de la asignatura Samfunnsfag su aplicación supera el marco nacional noruego y lo sustituye por una perspectiva universal, pero a la vez se limita al ámbito de la resolución de conflictos por cuanto se persigue que al finalizar el décimo y último curso de la enseñanza obligatoria el alumnado sea capaz de

explicar las causas y consecuencias de los conflictos históricos y contemporáneos centrales y reflexionar sobre si los cambios en algunas condiciones previas podrían haber prevenido los conflictos ${ }^{40}$.

Y en relación con la asignatura Historie los objetivos competenciales incorporan el recurso al pensamiento contrafáctico en el aula de historia prescindiendo igualmente de cualquier limitación geográfica y vinculándolo al ámbito de la valora-

kunne ha vorte dersom desse hendingane hadde utvikla seg annleis» (https://www.udir.no/kl06/ SAF1-01/Hele/Kompetansemaal/etter-10.-arssteget y https://www.udir.no/kl06/SAF1-02/Hele/ Kompetansemaal/etter-10.-arssteget respectivamente). Una segunda revisión, introducida en 2013 (Samfunnsfag [SAF1-03]), conservó básicamente el mismo texto al sustituir únicamente el término "reflexionar» por «discutir»: «finne døme på hendingar som har vore med på å forme dagens Noreg, og diskutere korleis samfunnet kunne ha vorte dersom desse hendingane hadde utvikla seg annleis» (https://www.udir.no/kl06/SAF1-03/Hele/Kompetansemaal/ kompetansemal-etter-10.-arssteget).

39 Læreplan i historie (HIS01-01) (2006): «finne eksempler på hendelser som har formet et ikke-europeisk lands historie etter 1900, og reflektere over hvordan landet kunne ha utviklet seg hvis disse hendelsene ikke hadde funnet sted» (https://www.udir.no/kl06/HIS1-01/Hele/ Kompetansemaal/kompetansemal-etter-vg3-i-studieforberedende-utdanningsprogram). La posterior revisión de 2009 (Læreplan i historie [HIS01-02]) conservó el texto en los mismos términos y así sigue vigente en la actualidad hasta la introducción del nuevo plan de estudios en Vg2 durante el próximo año escolar 2021/2022 y en Vg3 al siguiente (https://www.udir.no/kl06/ HIS1-02/Hele/Kompetansemaal/etter-vg3-studieforberedende-utdanningsprogram).

40 Samfunnsfag (SAF1-04) (2020): "gjere greie for årsaker til og konsekvensar av sentrale historiske og notidige konfliktar og reflektere over om endringar av nokre føresetnader kunne ha hindra konfliktane» (https://www.udir.no/lk20/saf01-04/kompetansemaal-og-vurdering/kv147). 
ción de las posibilidades existentes para actuar de un modo u otro en determinado contexto histórico y la consiguiente toma de decisiones por parte de los individuos envueltos en él tanto en términos generales como más concretamente en relación asimismo con la resolución de conflictos por cuanto se persigue que al finalizar el tercer y último curso de la educación secundaria superior el alumnado sea capaz de

investigar acerca de un personaje histórico y discutir su mentalidad, su margen de maniobra y sus opciones a la luz de la época en que vivió ${ }^{41}$,

así como de

investigar el margen de maniobra y de elección de los seres humanos en situaciones de conflicto y evaluar las consecuencias de las decisiones que han tomado ${ }^{42}$.

De igual modo, en los nuevos planes de estudios la consecución de tales objetivos, tal como se recoge en la evaluación de la adquisición de competencias correspondiente a la materia de historia tanto al finalizar la enseñanza obligatoria como al finalizar la educación secundaria superior, es considerada en función precisamente del recurso al razonamiento contrafáctico a través de la identificación y valoración de opciones y posibilidades alternativas respecto de la historia conocida. Así, en la asignatura Samfunnsfag el hecho de alcanzar tales metas obtiene un reconocimiento cada vez más positivo conforme aumenta el grado de complejidad de la reflexión por parte del alumno y éste «explica las opciones de acción planteadas en el pasado, presente y futuro» (grado bajo de adquisición de la competencia), "explica alternativas de acción en el pasado, presente y futuro y las consecuencias de éstas» (grado medio) o «explica las opciones de acción en el pasado, presente y futuro y las consecuencias de éstas e identifica matices» (grado alto) ${ }^{43}$. Y lo mismo sucede en la asignatura Historie cuando el alumno «proporciona ejemplos de cómo las opciones de las personas en el pasado estaban limitadas por el tiempo en el que vivieron y las

${ }^{41}$ Læreplan i historie (HIS01-03) (2020): «utforske en historisk person og diskutere hans eller hennes tenkning, handlingsrom og valg i lys av samtiden han eller hun levde i» (https:// www.udir.no/lk20/his01-03/kompetansemaal-og-vurdering/kv85).

42 Ibid.: «utforske menneskers handlingsrom og valgmuligheter i konfliktsituasjoner og vurdere konsekvenser av valgene de har tatt».

43 Kjennetegn på måloppnåelse - samfunnstag 10. trin: «Eleven forklarer gitte handlingsalternativer $\mathrm{i}$ fortid, nåtid og fremtid» (Lav kompetanse $\mathrm{i}$ faget, karakteren 2); "Eleven forklarer handlingsalternativer i fortid, nåtid og fremtid og konsekvenser av disse» (God kompetanse i faget, karakter 4); "Eleven forklarer handlingsalternativer i fortid, nåtid og fremtid og konsekvenser av disse, og identifiserer nyanser» (Framifrå kompetanse i faget, karakter 6) (https://www.udir.no/laring-og-trivsel/lareplanverket/kjennetegn/kjennetegn-pamaloppnaelse-samfunnsfag-10-trinn/). 
compara con las suyas» (grado bajo de adquisición de la competencia), «muestra cómo las elecciones de las personas en el pasado estuvieron caracterizadas y limitadas por el tiempo en el que vivieron y compara estas elecciones con las suyas» (grado medio) o «muestra las posibilidades de acción de las personas del pasado presentando la historia con diferentes resultados y reflexiona sobre el hecho de que sus propias elecciones también dependen del contexto» (grado alto) ${ }^{44}$.

Desde el primer momento la incorporación de la reflexión contrafáctica al currículo recibió la bienvenida por parte de los profesionales de la enseñanza de la historia, si bien no tanto por la novedad del planteamiento - pues hasta entonces no habían faltado docentes que recurriesen a él en sus aulas e incluso algunos libros de texto ya incorporaban actividades de este tipo ${ }^{45}$-, sino por el reconocimiento oficial de su valor didáctico que tal decisión implicaba. Al poco de ser aprobada la reforma de 2006, el especialista en didáctica de la historia Harald F. Skram elogiaba la presencia de la historia contrafáctica «por primera vez en la escuela» en un artículo precisamente así titulado en el que subrayaba su utilidad para investigar las relaciones causa-consecuencia -y particularmente la multicausalidad-y destacaba el valor del razonamiento contrafáctico en tanto que «experimento mental emocionante», tal como ya lo habían advertido los primeros docentes que en la década de 1960 dieron a conocer sus experiencias al respecto (Skram, 2008, p. 53; 2011, p. 19). Posteriormente la reflexión contrafáctica ha sido analizada en tanto que recurso educativo en el manual de didáctica de la historia elaborado por Lise Kvande y Nils Naastad $\left(2020^{2}\right)$, los cuales la asocian igualmente con la identificación de las relaciones

${ }^{44}$ Kjennetegn på måloppnåelse - historie Vg3 / Vg3 påbygging: «Eleven gjengir eksempler på at menneskers valgmuligheter $\mathrm{i}$ fortiden var begrenset av tiden de levde iog sammenligner disse valgmulighetene med egne» (Lav kompetanse i faget, karakteren 2); «Eleven viser hvordan menneskers valgmuligheter $i$ fortiden var preget og begrenset av tiden de levde i. og sammenligner disse valgmulighetene med egne» (God kompetanse i faget, karakter 4); "Eleven viser fortidens menneskers handlingsmuligheter ved å framstille historie med ulike utfall og reflekterer over at egne valg også er kontekstavhengig» (Framifrå kompetanse i faget, karakter 6) (https://www. udir.no/laring-og-trivsel/lareplanverket/kjennetegn/kjennetegn-pa-maloppnaelse-historie-vg3og-vg3pabygging/).

45 Implícitamente en los manuales editados en 1998 y 1999 por Fagbokforlaget dentro de la serie Kosmos para los cursos 9. y 10. de la enseñanza obligatoria en relación con el hundimiento del crucero alemán Blücher durante la invasión de Noruega en 1940 y con la crisis de los misiles de Cuba (J. H. Nomedal, Kosmos 9: geografi, historie og samfunnskunnskap y Kosmos 10: geografi, historie og samfunnskunnskap. Oslo, pp. 183 y 133 respectivamente apud Bjerke-Hagen, 2011, p. 33) y de manera explícita en el libro de texto de historia editado en 2000 por Aschehoug para educación secundaria superior al plantear al alumnado la cuestión «¿Qué hubiera pasado en Noruega si no hubiera sido posible emigrar?» («Hva ville ha skjedd i Norge dersom det ikke hadde vært mulig å utvandre?», F. Olstad, Veier til vår tid. Norgeshistorie etter 1850. Oslo, p. 32 apud Ask, 2009, pp. 67 y 107). 
de causalidad ${ }^{46}$. Pero también ha recibido una particular atención por parte de las investigaciones desarrolladas por los futuros docentes para obtener las titulaciones académicas de Máster que los habilitan profesionalmente, enmarcadas tanto en general en el ámbito educativo (Manum, 2016) o en el de las ciencias sociales (a través de los juegos de rol en Evensen, 2018) como más concretamente en el de la didáctica de la historia y, dentro de este último, bien para investigar acerca de la respuesta que despierta entre los docentes en ejercicio -desde un optimismo casi entusiasta al ver en ella un desafío especialmente estimulante hasta un escepticismo crítico dada la muy probable carencia de los conocimientos suficientes por parte del alumnado y del tiempo necesario por parte de esos mismos docentes (Paulssen, 2011; Vassbotn, 2014; Ytreb $\varnothing, 2019$ )-, para apuntar su presencia en los libros de texto (Ask, 2009; Moesgaard, 2011) o para defender su valor didáctico junto con la ficción y la cultura popular (Schei Medrano, 2020), bien por su vinculación con el desarrollo del pensamiento crítico entre el alumnado (Reinsve, 2018) o con la utilización de videojuegos en el aula (Lavold, 2016; Stensletten, 2017; Clausen Waage, 2019). Entre estas últimas destaca el estudio de Marius Bjerke-Hagen por cuanto, bajo el título Kontrafaktisk historie i undervisning: nyttig undervisningsmetode eller rent tidsfordriv? ("La historia contrafáctica en la enseñanza: ¿método de enseñanza útil o puro pasatiempo?»), aborda la cuestión de manera específica. En primer lugar define qué es la historia contrafáctica y explora su relación con la historia real, los argumentos que encuentra en los ámbitos de la psicología y la pedagogía y su vinculación con el desarrollo de la conciencia histórica. Seguidamente analiza su introducción en el currículo noruego a partir de la reforma de 2006, realiza una pequeña investigación acerca de su recepción en el aula mediante la utilización de un cuestionario con alumnado de los cursos 9. y 10.9 y apunta requisitos que condicionan la utilidad del recurso tales como la imprescindible exigencia de verosimilitud histórica de las alternativas propuestas, los temas más adecuados para elaborarlas, la recomendación de hacerlo bajo la forma de trabajo en grupo, la edad aconsejable en el caso del alumnado participante y los conocimientos previos necesarios tanto entre ese mismo alumnado como entre los docentes. Y finalmente hace referencia a la presencia de la reflexión contrafáctica en los manuales escolares de la asignatura Samfunnsfag publicados por tres conocidas editoriales tras la reforma de $\mathbf{2 0 0 6}$ mediante la selección de algunos ejemplos recogidos en los volúmenes correspondientes a los tres cursos de la educación secundaria básica con los cuales se completa la enseñanza obligatoria (Bjerke-Hagen, 2011) 47 $^{\text {, un }}$ ámbito de especial interés en el tema que nos ocupa.

${ }^{46}$ Kvande y Naastad $\left(2020^{2}\right)$, cap. 8, Historie som prosess og sammenheng ("La historia como proceso y contexto»), pp. 203-222.

47 En un trabajo anterior (Pelegrín Campo, 2014b) ya hemos comentado el análisis elaborado por Bjerke-Hagen a partir de los manuales escolares correspondientes a los cursos 8., 9.ㅇ y 10. o publicados entre 2006 y 2008 en las series Underveis (ed. Gyldendal), Makt og menneske (ed. Cappelen Damm) y Kosmos (ed. Fagbokforlaget). 


\section{LA REFLEXIÓN CONTRAFÁCTICA EN LOS LIBROS DE TEXTO NORUEGOS DE CIENCIAS SOCIALES Y DE HISTORIA}

Ciertamente, la elevación oficial del razonamiento contrafáctico a la categoría de herramienta didáctica como consecuencia de su incorporación al currículo encuentra una manifestación especialmente interesante en su acogida en los libros de texto de historia asociados a las etapas educativas entre cuyos objetivos competenciales figura el desarrollo de este tipo de recurso, y con mayor razón dada la asociación existente entre esta práctica y la importancia concedida en los manuales escolares a actividades orientadas a desarrollar el pensamiento crítico entre el alumnado (Helgason, 2010, p. 165). En ese sentido Bjerke-Hagen critica no tanto el limitado número de actividades de este tipo que se observa en la serie Underveis editada por Gyldendal para los tres cursos de la educación secundaria básica, sino sobre todo la escasa utilidad didáctica derivada de su falta de continuidad, pues los dos únicos ejercicios de carácter contrafáctico que plantea -centrados en construir y comparar con la Noruega actual sendas alternativas a la separación respecto de Dinamarca en 1814 y a la independencia en $1905^{48}$ - figuran en el volumen destinado a 8. curso, cuando en los manuales publicados por otras editoriales con destino a esos mismos tres últimos cursos de la enseñanza obligatoria el recurso a la reflexión contrafáctica no solo figura en todos ellos, sino que aumenta progresivamente desde 8.0 hasta 10. o tanto en términos cuantitativos como cualitativos y paralelamente al cada vez mayor grado 1 ) de complejidad de los acontecimientos y de los procesos históricos abordados, 2) de profundización en las connotaciones éticas que se derivan de cada una de las alternativas propuestas y 3 ) de la capacidad del alumnado para argumentar el planteamiento, desarrollo y resultado de cada una de ellas (Bjerke-Hagen, 2011, pp. 33-34 y 65-66).

Así, en la serie Makt og Menneske editada por Cappelen Damm el volumen correspondiente al 8. curso pregunta al alumnado acerca de las posibles consecuencias de una campaña napoleónica de Rusia más favorable y de una Noruega sin la constitución de 1814 o sin la modernización agrícola desarrollada durante el siglo

${ }^{48}$ H. Skjønsberg (2006). Underveis. Historie 8. Oslo: Gyldendal, p. 77: «Forestill deg at unionen med Danmark aldri var blitt oppløst. Hva hadde vært likt, og hva hadde vært forskjellig i livet ditt da?» («Imagina que la unión con Dinamarca nunca se hubiera disuelto. ¿Qué habría sido similar y qué habría sido diferente en tu vida en ese caso?»); p. 191: «Tenk deg at Sverige har akseptert Norges krav under forhandlingene, og at landene hadde fortsatt i unionen. Hva ville vært likt, og hva ville vært forskjellig? Hvem ville vært konge? Hvordan ville flagget vårt se ut? Finn andre ting som hadde vært likt, og andre ting som hadde vært ulikt. Sammenlign med i dag!» («Imagina que Suecia ha aceptado las demandas de Noruega durante las negociaciones y que los países han permanecido en la unión. ¿Qué sería igual y qué sería diferente? ¿Quién sería el rey? ¿Cómo sería nuestra bandera? Encuentra otras cosas que hayan sido similares y otras cosas que hayan sido diferentes. ¡Compara con las de hoy!»); Bjerke-Hagen (2011), pp. 30-31 y 65-66. 
$\mathrm{XIX}^{49}$. El de 9. 0 sugiere como escenarios alternativos de la Segunda Guerra Mundial una Finlandia apoyada por los Aliados contra Stalin durante la denominada Guerra de Invierno en noviembre de 1939, un Mediterráneo controlado por Italia tras la victoria del Eje y un acuerdo de paz diferente en Noruega tras el final de guerra ${ }^{50}$. $Y$ el de 10. - aborda escenarios lo mismo nacionales que internacionales para plantear como alternativas en el primer caso una Noruega revolucionaria durante el período de Entreguerras, no integrada en la OTAN o sin la riqueza del petróleo y el gas del mar del Norte ${ }^{51}$, y en el segundo un ataque nuclear norteamericano contra

49 B. Ingvaldsen e I. Kristensen (2006). Makt og Menneske. Historie 8. Oslo: Cappelen Damm, tema 3 Krig og må fred stoppes! («iLa guerra y la paz deben ser detenidas!»), apartado Slaget er tapt («La batalla está perdida»), p. 59: «Hva tror du ville ha skjedd dersom Napoleon ikke hadde møtt alle disse problemene?» («¿Qué crees que hubiera pasado si Napoleón no se hubiera enfrentado a todos estos problemas?»); ibid., tema 4 Fra union til union - Norge får egen grunnlov («De la unión a la unión - Noruega tiene su propia constitución»), pp. 62 (subtítulo) y 79, sección Oppgave («Ejercicio»), ejercicio 4 (para realizar por parejas y exponer ante el resto de la clase): «Hva hadde skjedd dersom Norge ikke hadde fått sin egen grunnlov i 1814? Hadde Norge vært annerledes dersom vi ikke hadde fått en grunnlov i 1814?» («¿Qué hubiera pasado si Noruega no hubiera tenido su propia constitución en 1814? ¿Noruega habría sido diferente si no hubiéramos tenido una constitución en 1814?»); ibid., tema 5 Maskinene kommer! («iLlegan las máquinas!»), p. 87, sección Spørsmål («Preguntas»), pregunta 6: «Hva tror du ville ha skjedd dersom endringene i jordbruket ikke hadde kommet før rundt 1900?» ("¿Qué crees que hubiera sucedido si los cambios en la agricultura no se hubieran producido antes de 1900?»).

50 B. Ingvaldsen e I. Kristensen (2007). Makt og Menneske. Historie 9. Oslo: Cappelen Damm, tema 5 Den store fedrelandskrigen ("La gran guerra patria»), p. 93, sección Spørsmål («Preguntas»), pregunta 3: «Hva hadde skjedd dersom de allierte hadde gjennomført planene om å hjelpe Finland? Bruk fantasien og lag en hypotese» («¿Qué hubiera pasado si los Aliados hubieran puesto en marcha planes para ayudar a Finlandia? Usa la imaginación y construye una hipótesis»); ibid., tema 5, sección Italienerne trenger tysk hjelp ("Los italianos necesitan ayuda alemana»), p. 102: «Hvilke følger ville italiensk kontroll over Middelhavet ha fått for Storbritannia etter at krigen var slutt?» («¿Qué consecuencias habría tenido el control italiano del Mediterráneo para Gran Bretaña después del final de la guerra?»); ibid., tema 7 «Krigen er over oss» («La guerra está sobre nosotros»), sección Oppgjørets time («Tiempo de liquidación»), p. 147: «Hvordan foregikk fredsoppgjøret? Kunne det norske fredsoppgjøret ha vært gjennomført annerledes? Begrunn svaret» (“¿Cómo se llevó a cabo el acuerdo de paz? ¿Podría haberse llevado a cabo de otra manera el acuerdo de paz noruego? Justifica la respuesta»).

${ }^{51}$ B. Ingvaldsen e I. Kristensen (2008). Makt og Menneske. Historie 10. Oslo: Cappelen Damm, tema 1 Det moderne Norge («La Noruega moderna»), apartado Politisk turbulens revolusjon i Norge? («Turbulencia política: ¿revolución en Noruega?»), p. 12, sección Spørsmål («Preguntas»), pregunta 4: «Hvordan tror du det hadde vært i Norge om det virkelig hadde skjedd en revolusjon?» («¿Cómo crees que hubiera sido en Noruega si realmente hubiera habido una revolución?»); ibid., tema 1, apartado Den kalde krigen ("La guerra fría»), p. 21, sección Spørsmål («Preguntas»), pregunta 3: "Hvordan tror du det hadde vært i Norge i dag om landet ikke var blitt medlem av Nato?» («¿Cómo crees que hubiera sido Noruega hoy si el país no se hubiera convertido en miembro de la OTAN?»); ibid., tema 1, apartado Nye tider - Norge inn i EF? («Nuevos tiempos: ¿Noruega en la CEE?»), p. 25, sección Spørsmål («Preguntas»), pregunta 
China durante la Guerra de Corea y una solución diferente a la crisis de los misiles de Cuba ${ }^{52}$, propuestas a las que, tras solicitar al alumnado que construya preguntas utilizando las conocidas como $5 \mathrm{~W}$-quién, qué, dónde, cuándo y por qué- en relación con los temas de la desintegración de Yugoslavia, el conflicto palestino-israelí, la guerra entre Irak e Irán, la Guerra del Golfo y la guerra de Irak, se suma el ejercicio consistente en completar la pregunta de carácter contrafáctico «¿qué hubiera pasado si ... no ...?» en relación con el primero de esos temas y de hacer lo mismo según la doble fórmula «¿qué hubiera pasado si [+ seleccionar un acontecimiento o un conjunto de ellos] hubiera / no hubiera [+ seleccionar una acción]?» en relación con los restantes ${ }^{53}$.

De un modo similar, en la serie Kosmos editada por Fagbokforlaget el volumen correspondiente a 8.ㅇ plantea cuestiones de carácter contrafáctico en relación con un desarrollo alternativo de la revolución francesa y con las consecuencias del estallido de un fenómeno similar al francés en Noruega ${ }^{54}$. Pero también lo hace más allá

2: «Hva tror du hadde vært den største næringen i Norge dersom det ikke var blitt funnet olje og gass på norsk sokkel?» ("¿Cuál crees que hubiera sido la industria más grande de Noruega si no se hubiera encontrado petróleo y gas en la plataforma noruega?»).

52 Ibid., tema 4 Mistro og mistenksomhet - da verden holdt pusten («Desconfianza y sospecha: cuando el mundo contuvo la respiración»), apartado Koreakrigen («La guerra de Corea»), p. 80, sección Spørsmål («Preguntas»), pregunta 4: «Hva tror du hadde skjedd dersom general MacArthur hadde brukt atomvåpen mot Kina?» ("Qué crees que hubiera sucedido si el general MacArthur hubiera usado armas nucleares contra China?»); ibid., tema 4, apartado Krigen kan ikke vinnes! («iLa guerra no se puede ganar!»), p. 87, sección Spørsmål («Preguntas»), pregunta 3: "Hva kunne ha skjedd hvis Kennedy hadde valgt en annen løsning enn blokade av Cuba?» («¿Qué hubiera pasado si Kennedy hubiera optado por una solución distinta al bloqueo a Cuba?»).

53 Ibid., tema 5 Jugoslavia eksploderer («Yugoslavia explota»), apartado Verdenssamfunnet prøver å hjelpe («La sociedad mundial intenta ayudar»), p. 109, sección Oppgave 4 («Ejercicio 4»), cuestión B.3: «Lag et spørsmål ved å fullføre denne setningen: Hva hadde skjedd dersom ikke . Nå lar du en medelev svare på spørsmålene dine. Diskuter svarene» («Haz una pregunta completando esta oración: ¿Qué hubiera pasado si no ? Ahora deja que un compañero de clase responda tus preguntas. Discute las respuestas»); ibid., tema 6 Midtøsten - det vanskelige konfliktområdet («Oriente Medio: la difícil zona de conflicto»), p. 119, sección Oppgave 1 («Ejercicio 1»), cuestión A.3: «Fyll ut de tomme rommene i disse setningene slik at de blir til spørsmål: a) Hva hadde skjedd dersom _[en hendelse eller ei gruppe]_ hadde _[en handling]_? b) Hva hadde skjedd dersom _[en hendelse eller ei gruppe]_ikke hadde _[en handling]_?» ("Completa los espacios en blanco en estas oraciones para que se conviertan en preguntas: a) ¿Qué hubiera pasado si _[un acontecimiento o un conjunto de acontecimientos]_ hubiera_[una acción]_? b) ¿Qué hubiera pasado si _[un acontecimiento o un conjunto de acontecimientos]_no hubiera_[una acción]_?»).

${ }^{54}$ J. H. Nomedal (2006). Kosmos 8. Samfunnsfag fur ungdomstrinnet. Oslo: Fagbokforlaget, bloque Historie, tema 3 1789-Den franske revolusjonen («1789-La revolución francesa»), p. 152, sección Tenk selv («Piensa por ti mismo»), cuestión 5: «Hvordan tror du utviklingen i Frankrike 
del ámbito estrictamente histórico para estimular la reflexión del alumnado acerca de cuestiones tales como un planeta Tierra sin efecto invernadero o la importancia que para una democracia tiene evitar la concentración excesiva de poder, dentro de los bloques de la asignatura dedicados a la geografía y a las ciencias sociales respectivamente $^{55}$. El de 9.o pregunta acerca de las consecuencias para Noruega y Europa en la actualidad si en 1905 la independencia hubiese instaurado un sistema republicano en el caso de la primera y si la Segunda Guerra Mundial hubiese finalizado con la victoria de Alemania en el de la segunda, conflicto este último a propósito del cual se propone discutir además si los planes de Hitler podrían haber sido frenados antes del inicio de las hostilidades ${ }^{56}$, pero de nuevo aplica el razonamiento contrafáctico más allá de lo propiamente histórico y dentro del bloque correspondiente al área de ciencias sociales para indagar acerca de las consecuencias del consumo

hadde blitt hvis tredjestanden hadde godtatt den gamle måten å stemme på?» («¿Cómo crees que hubiera sido la evolución en Francia si el tercer estado hubiera aceptado la antigua forma de votar?»); ibid., tema 4 Napoleon - en krigsglad herre («Napoleón: un señor belicoso»), p. 166 (introducción): «Hvordan tror du forholdet hadde vært mellom folk i Norge hvis vi hadde opplevd det franskmennene gjorde under den franske revolusjonen?» («¿Cómo crees que hubiera sido la relación entre la gente de Noruega si hubiéramos experimentado lo que hicieron los franceses durante la revolución francesa?»).

55 Ibid., bloque Geografi, tema 12 Natur og samfunn på kollisjonskurs («Naturaleza y sociedad en curso de colisión»), p. 82, sección Finn svar i teksten («Encuentra respuestas en el texto»), tarea 4: "Hva er middeltemperaturen på jorda? Hva ville den vært hvis det ikke hadde vært en drivhuseffekt?» («¿Cuál es la temperatura media de la tierra? ¿Cómo sería si no hubiera sido por el efecto invernadero?»); ibid., bloque Samfunnskunnskap, tema 7 Demokrati som styreform («La democracia como forma de gobierno»), p. 264, sección Tenk selv («Piensa por ti mismo»), cuestión 1: «Snakk sammen i par om hvordan det ville vært på skolen eller i klassen hvis én person skulle hatt all makt og bestemt alt som skulle skje. Hvorfor er det viktig at ingen får for mye makt i et land?» («Hablad por parejas acerca de cómo sería en la escuela o en clase si una persona tuviera todo el poder y decidiera todo lo que iba a suceder. ¿Por qué es importante que nadie obtenga demasiado poder en un país?»).

56 J. H. Nomedal y S. Bråthen (2007). Kosmos 9. Samfunnsfag fur ungdomstrinnet. Oslo: Fagbokforlaget, bloque Historie, tema 1 Fra union til selvstendig nasjon («De unión a nación independiente»), p. 106, sección Tenk selv («Piensa por ti mismo»), cuestión 9: «Hva ville vært annerledes i Norge i dag dersom et flertall ved folkeavstemningen i 1905 hadde stemt for republikk?» ("¿Qué habría sido diferente en Noruega hoy si una mayoría en el referéndum de 1905 hubiera votado por una república?»); ibid., tema 5 Den andre verdenskrigen 1939-1945 ("La segunda guerra mundial 1939-1945»), p. 166, sección Tenk selv («Piensa por ti mismo»), cuestión 4: «Diskuter i gruppa: a) Hvordan tror dere Europa hadde sett ut i dag hvis tyskerne hadde vunnet krigen?» («Discutid en grupo: a) ¿Cómo creéis que habría sido Europa hoy si los alemanes hubieran ganado la guerra?»); ibid., tema 5, p. 161, sección Tenk selv («Piensa por ti mismo»), cuestión 3: «Drøft om Storbritannia og Frankrike kunne ha stoppet Hitler på et tidligere tidspunkt. Hva kunne ha skjedd dersom de hadde grepet inn tidligere?» («Discute si Gran Bretaña y Francia pudieron haber detenido a Hitler en una etapa anterior. ¿Qué podría haber pasado si hubieran intervenido antes?»). 
de alcohol en el comportamiento de los adolescentes y de las responsabilidades derivadas de ello, así como sobre el funcionamiento del "Consejo de conflictos» (Konfliktrådet) instaurado en Noruega para resolver delitos menores mediante acuerdos y sin recurrir a procesos judiciales ${ }^{57}$. Y el de 10. 0 sugiere construir alternativas históricas que toman como punto de partida en el plano internacional la no intervención de Estados Unidos en Vietnam, el mantenimiento del control soviético sobre Europa del Este con Mijail Gorbachov, la ausencia de la Guerra Fría en Europa y la continuidad del apartheid en Sudáfrica ${ }^{58}$, y en el marco nacional una Noruega

57 Ibid., bloque Samfunnskunnskap, tema 2 Alkohol, narkotika og tobakk («Alcohol, drogas y tabaco»), sección Alkohol («Alcohol»), apartado Folk har ulike holdninger til alkohol («Las personas tienen diferentes actitudes hacia el alcohol»), p. 224: «Noen tenåringer forbinder helg og fest med alkohol. (...) Merethe og Espen var begge påvirket av alkohol da de rota med hverandre. Tror du de hadde gjort det om de ikke hadde drukket? Kan alkoholen noen ganger brukes som en unnskyldning for visse handlinger?» ("Algunos adolescentes asocian los fines de semana y las fiestas con el alcohol. (...) Merethe y Espen estaban bajo la influencia del alcohol cuando se metieron entre ellos. ¿Crees que lo habrían hecho si no hubieran estado bebiendo? ¿Se puede usar el alcohol a veces como excusa para ciertas acciones?»); ibid., tema 3 Kriminalitet og straff ("Crimen y castigo»), sección Rettssystemet («El sistema judicial»), apartado Alternativet til konfliktrådet («La alternativa al consejo de conflictos»), p. 247: «Hva ville skjedd dersom butikkeieren ikke hadde ønsket å møte Sara i konfliktrådet? Eller om de ikke greide å komme til enighet?» («¿Qué hubiera pasado si el dueño de la tienda no hubiera querido reunirse con Sara en el consejo de conflictos? ¿̇ si no lograran llegar a un acuerdo?»).

58 J. H. Nomedal y S. Bråthen (2007). Kosmos 10. Samfunnsfag fur ungdomstrinnet. Oslo: Fagbokforlaget, bloque Historie, tema 1 Kald krig - en todelt verden («Guerra Fría: un mundo en dos partes»), apartado Den kalde krigen spredte seg til resten av verden («La Guerra Fría se extendió al resto del mundo»), p. 125, sección Tenk selv («Piensa por ti mismo»), cuestión 10: «Diskuter i klassen: a) Hvorfor valgte USAs myndigheter å gå til krig i Vietnam? b) Hva synes du om begrunnelsene deres? c) Hva tror du hadde skjedd dersom de ikke hadde blandet seg inn i konflikten i Vietnam?» («Discute en clase: a) ¿Por qué el gobierno de Estados Unidos decidió ir a la guerra en Vietnam? b) ¿Qué opinas de sus motivos? c) ¿Qué crees que hubiera pasado si no hubieran intervenido en el conflicto de Vietnam?»); ibid., tema 1, apartado Hvorfor tok den kalde krigen slutt? («¿Por qué terminó la Guerra Fría?»), p. 130, sección Tenk selv («Piensa por ti mismo»), cuestión 7: "Hvordan tror du historien hadde utviklet seg dersom Gorbatsjov hadde beholdt jerngrepet om $\varnothing$ st-Europa? Skriv en kort tekst om hvordan du tror $\emptyset$ st-Europa hadde vært» ("¿Cómo crees que se habría desarrollado la historia si Gorbachov hubiera mantenido el férreo control sobre Europa del Este? Escribe un texto breve sobre cómo crees que habría sido Europa del Este»); ibid., p. 131, cuestión 13: «Hvordan ville Europa sett ut i dag dersom den kalde krigen aldri hadde funnet sted? Skriv ned ti påstander og del dem med klassen» («¿Cómo sería Europa hoy si la Guerra Fría nunca hubiera tenido lugar? Escribe diez afirmaciones y compártalas con la clase»); ibid., tema 3 Koloniene ble selvstendige ("Las colonias se independizaron»), p. 161, sección Tenk selv («Piensa por ti mismo»), cuestión 12: "Apartheidregimet ble avskaffet på fredelig vis i Sør-Afrika. Hva ville skjedd dersom det hvite styret hadde tviholdt på makta? Lag en tekst der du beskriver hvordan du tror det ville gått» («El régimen del apartheid fue abolido pacíficamente en Sudáfrica. ¿Qué hubiera pasado si el gobierno blanco hubiera permanecido en el poder? Haz un texto que describa cómo crees que sería»). 
sin petróleo en el mar del Norte o que en 1994 vota mayoritariamente a favor de su integración en la Unión Europea ${ }^{59}$. En relación con este último contexto también propone al alumnado elegir diez acontecimientos de la historia noruega posteriores a 1945 y pensar en devenires alternativos en cada uno de ellos y elegir tres acontecimientos de los últimos dos siglos y comparar la alternativa resultante con la situación actual ${ }^{60}$. Y finalmente, de nuevo en ámbitos ajenos a lo estrictamente histórico, plantea sendas hipótesis a propósito de la situación en una escuela en la que no se respetaran las normas y de las consecuencias que para la agricultura noruega tendría la liberalización del comercio a nivel mundial ${ }^{61}$.

59 Ibid., tema 6 Norge utviklet velferdsstaten («Noruega desarrolló el estado de bienestar»), apartado 1965-1980 - Velferdsstat og oljeeventyr ( «1965-1980 - Estado del bienestar y aventura petrolera»), p. 211, sección Tenk selv («Piensa por ti mismo»), cuestión 11: "Tenk deg at det aldri hadde blitt funnet olje i Nordsjøen. Kunne dette på noen måte vært fordelaktig for Norge?» («Imagínate que nunca se hubiera encontrado petróleo en el Mar del Norte. ¿Podría haber sido esto beneficioso para Noruega de alguna manera?»); ibid., tema 6, apartado 1981-1994 Marked mot stat («1981-1994 - Mercado contra estado»), p. 215, sección Tenk selv («Piensa por ti mismo»), cuestión 4: «l 1994 sa det norske folk nei til medlemskap i EU. På hvilken måte tror du Norge ville vært annerledes dersom vi hadde blitt medlemmer? Diskuter i klassen» («En 1994, la población noruega dijo no al ingreso en la UE. ¿De qué manera crees que Noruega habría sido diferente si nos hubiéramos convertido en miembros? Discútelo en clase»).

60 Ibid., tema 6 Norge utviklet velferdsstaten («Noruega desarrolló el estado de bienestar»), apartado Norge etter 1995 - Velferdsstaten under press («Noruega después de 1995: el estado del bienestar bajo presión»), p. 222, sección Tenk selv («Piensa por ti mismo»), cuestión 7: «Velg deg ut de ti viktigste begivenhetene for Norge i perioden etter 1945. Husk at du må begrunne hvorfor du mener at disse ti begivenhetene er de viktigste. Hvordan ville Norge ha sett ut i dag, dersom utviklingen hadde tatt en annen vei i disse tilfellene? Diskuter med de andre i gruppa etterpå» («Elige los diez eventos más importantes para Noruega en el período posterior a 1945. Recuerda que debes justificar por qué crees que estos diez eventos son los más importantes. ¿Cómo habría sido Noruega hoy si la evolución hubiera tomado un camino diferente en estos casos? Después discútelo con los demás en el grupo»); ibid., cuestión 13: "Hvilke tre begivenheter de siste to hundre år har vært mest avgjørende for hvordan Norge ser ut i dag? Hva ville vært annerledes i dag dersom utviklingen hadde gått i en annen retning? Skriv en tekst der du reflekterer rundt disse spørsmålene» («¿Qué tres eventos en los últimos doscientos años han sido más decisivos para el aspecto actual de Noruega? ¿Qué habría sido diferente hoy si el desarrollo hubiera ido en una dirección diferente? Escribe un texto en el que reflexiones sobre estas preguntas»).

61 Ibid., bloque Samfunnskunnskap, tema 1 Samfunnet - der kulturer møtes («Sociedad: donde las culturas se encuentran»), sección Du er en del av flere samfunn («Formas parte de varias comunidades»), p. 225: "Hva ville skjedd dersom ingen på skolen fulgte de reglene som gjelder?» ("¿Qué pasaría si nadie en la escuela siguiera las reglas que se aplican?»); ibid., tema $2 \varnothing$ konomi - mer enn penger («Economía: más que dinero»), p. 272, sección Tenk selv («Piensa por ti mismo»), cuestión 10: "Hva tror du ville skje med norsk landbruk dersom det var full frihandel?» ("¿Qué crees que le pasaría a la agricultura noruega si hubiera un libre comercio total?»). 
Paralelamente, por lo que se refiere a los libros de texto correspondientes a la educación secundaria superior, Liv Ask fue la primera en referirse a la presencia de cuestiones de carácter contrafáctico en los primeros manuales de la asignatura Historie publicados conforme a la reforma de 2006, concretamente a propósito de los acontecimientos que tuvieron lugar en Noruega en 1814 tal como son presentados en las series Portal y Tidslinjer editadas por Fagbokforlaget y Aschehoug ${ }^{62}$, si bien no encontramos mención alguna a este recurso en los publicados por Cappelen Damm, tanto en las ediciones de 2007 y 2008 destinadas respectivamente a esos cursos por separado como en la versión editada en 2013 para ambos en un único volumen ${ }^{63}$. Por el contrario, y precisamente en uno de los casos mencionados por Ask, la serie Tidslinjer editada por Aschehoug por separado para Vg2 y para Vg3 en esos mismos años 2007 y 2008 y en un solo volumen para los dos cursos en 2011 ofrece un tratamiento modélico del tema. Para empezar introduce este recurso en el colofón del tema dedicado en Vg2 a Asia y Oriente Medio en época medieval cuando, al cuestionar la visión eurocéntrica de la historia y evocar el dominio persa y árabe de las rutas comerciales en torno al océano Índico entre los siglos VIII y XV, explica en primer lugar qué es la historia contrafáctica ${ }^{64}$, plantea seguidamente la cuestión

62 O. A. Abrahamsen, S. Dyrvik, M.-B. Ohman Nielsen y A. Aase (2007). Portal. Nyere historie: Verdenshistorie og Norgeshistorie etter 1750. Oslo: Fagbokforlaget, p. 63: «Det er likevel fristende å komme med et lite kontrafaktisk spørsmål: Hva slags forfatning ville Norge ha fått dersom den norske oppstandelsen ikke hadde kommet, og dersom det helt fra februar 1814 hadde blitt ført forhandlinger med svenskene?» («Sin embargo, es tentador plantear una pequeña pregunta contrafáctica: ¿qué tipo de constitución habría recibido Noruega si no hubiese tenido lugar la insurrección noruega y si se hubieran llevado a cabo negociaciones con los suecos a partir de febrero de 1814?»); A. Øhren, E. Ertresvaag, H. Wiig, J. Eliassen, L. Skovholt, O. K. Grimnes y T. L. Eriksen (2008). Tidslinjer 2. Verden og Norge Historie Vg3. Oslo: Aschehoug, p. 87: «Vi har sett at Karl Johan kunne ha foretatt alternative valg som ville ha gitt norsk historie en annen retning. (...) I hvilken grad vil det endre historiens gang dersom personene som var involvert, hadde valgt annerledes? Synes du et er meningsfylt å leke med historien på denne måten?» («Hemos visto que Karl Johan podría haber tomado decisiones alternativas que hubieran dado a la historia de Noruega una dirección diferente. (...) ¿Hasta qué punto cambiaría el curso de la historia si las personas involucradas hubieran elegido de otra manera? ¿Crees que tiene sentido jugar con la historia de esta manera?»); apud Ask (2009), pp. 81 y 91-92 respectivamente.

${ }_{63}$ I. Libæk, $\varnothing$. Stenersen, A. Sveen y S. A. Aastad (2007). Historie Vg2. Fra de eldste tider til 1700-tallet. Oslo: Cappelen Damm; Eid. (2008). Historie Vg3. Fra 1700-tallet til i dag. Oslo: Cappelen Damm; Eid. (2013). Historia Vg2-3. Ettbindsutgaven. Oslo: Cappelen Damm.

64 J. Eliassen, O. Engelien, T. L. Eriksen, E. Ertresvaag, O. K. Grimnes, S. V. Hellerud, L. Skovholt, K. Sprauten, H. Wiig y A. Øhren (2011). Tidslinjer 1+2. Verden og Norge. Historie Vg2/ Vg3. Oslo: Aschehoug, tema 5 Asia og Midtøsten i middelalderen («Asia y Oriente Medio en la Edad Media»), sección final Perspektiver («Perspectivas») titulada Fra nasjonal historie til globalhistorie («De la historia nacional a la historia global»), p. 122: "I tillegg til at historikere velger å sammenligne det som faktisk fant sted i forskjellige land, slik vi har gjort i dette kapitlet, er det også noen som stiller spørsmål om hva som kunne ha skjedd. På fagspråket er det kjent 
«¿Cómo habría sido la historia mundial si China hubiera enviado su flota alrededor del mundo, conquistado colonias y cerrado a los competidores europeos los océanos del mundo? ${ }^{65}$ y concluye apuntando como tema de discusión la utilidad de la reflexión contrafáctica como recurso para alcanzar una mayor comprensión de la historia ${ }^{66}$. Más tarde el mismo volumen subraya la importancia que para la alimentación de los seres humanos en general representó el Descubrimiento de América y la expansión de los alimentos de allí orginarios por todo el mundo y, a modo de ejemplo especialmente significativo para el alumnado dada la proximidad del mismo a su vida cotidiana, pregunta “¿Qué habría sido de la pizza sin los tomates?» ${ }^{67}$. $Y$ finalmente, en lugar de presentar una situación alternativa e interrogar acerca de las consecuencias derivadas de ella, lo que se hace es plantear un resultado alternativo y preguntar acerca de las posibles causas que podrían haberlo motivado cuando en el curso Vg3 el tema dedicado al período de Entreguerras se cierra abordando la cuestión "¿Se podría haber evitado el ataque alemán a Noruega?» con el objetivo de descubrir hasta qué punto la falta de previsión en política exterior y de defensa de los sucesivos gobiernos noruegos de la época ante la actitud cada vez más agresiva de Alemania terminó facilitando el éxito de la invasión del 9 de abril de $1940^{68}$.

som kontrafaktiske hypoteser. Vi har så lett for å forestille oss at det som hendte i historien var nødt til å skje, (...) tenker ikke så ofte på at utviklingen kunne ha tatt en annen retning» ("Además de los historiadores que eligen comparar lo que realmente sucedió en diferentes países, como hemos hecho en este capítulo, también hay algunos que se preguntan qué pudo haber sucedido. En lenguaje técnico, se conocen como hipótesis contrafácticas. Es muy fácil para nosotros imaginar que lo que sucedió en la historia tuvo que suceder, [...] no se suele pensar que el desarrollo podría haber tomado una dirección diferente»).

65 Ibid.: «Ut fra dette vi har beskrevet ovenfor, kan vi for eksempel stille spørsmålet: Hvordan ville verdenshistorien ha sett ut om Kina hadde sendt flåten sin rundt hele jorden, erobret kolonier og stengt europeiske konkurrenter ute fra verdenshavene?» («A partir de lo que hemos descrito anteriormente, podemos, por ejemplo, hacer la pregunta: ¿cómo habría sido la historia mundial si China hubiera enviado su flota alrededor del mundo, conquistado colonias y cerrado a los competidores europeos los océanos?»).

${ }^{66}$ Ibid.: «Spфrsmålet til slutt i teksten ovenfor kalles kontrafaktisk. Det vil si at det dreier seg om det som ikke skjedde i historien, men som likevel kunne ha skjedd. Prøv å besvare spørsmålet gjennom å sette opp noen punkter. I hvilken grad synes du det gir økt innsikt å diskutere slike problemstillinger?» ("La pregunta final del texto anterior se denomina contrafáctica. Es decir, se trata de lo que no sucedió en la historia, pero que pudo haber sucedido. Intente responder la pregunta estableciendo algunos puntos. ¿En qué medida cree que proporciona una mayor comprensión para debatir estos temas?»).

67 Ibid., tema 8 Oppdagelser, kolonier og slavehandel («Descubrimientos, colonias y trata de esclavos»), sección Et økologisk verdenssystem («Un sistema mundial ecológico»), p. 206: «Hva ville vel pizza ha vært uten tomater?».

${ }^{68}$ Ibid., tema 17 De vanskelige mellomkrigsårene ("Los difíciles años de entreguerras»), sección final Perspektiver («Perspectivas») titulada "Aldri mer 9. april» («"Nunca más 9 de abril"»), p. 415: «Kunne det tyske angrepet på Norge ha vært unngått? (...) Hadde regjeringen 
A partir de este momento, y en especial tras la revisión parcial del currículo que en 2013 generó una nueva edición de los libros de texto, en la enseñanza obligatoria los manuales de la asignatura Samfunnsfag confirman tanto el recurso a la reflexión contrafáctica en el ámbito histórico como su extensión a los bloques asociados a la geografía y a las ciencias sociales que integran asimismo dicha asignatura $^{69}$. Por su parte, en la educación secundaria superior los de la asignatura Historie

tolket disse signalene riktig, ville den trolig ha styrket den militære beredskapen og mest sannsynlig ha mobilisert det norske forsvaret. Kanskje ville det ha redusert mulighetene for et tysk angrep eller for at angrepet ville ha blitt vellykket» («Si el gobierno hubiera interpretado correctamente estas señales, probablemente habría fortalecido la preparación militar y tal vez habría movilizado la defensa noruega. Quizás hubiera reducido las posibilidades de un ataque alemán o de que el ataque hubiera tenido éxito»).

69 Durante los cursos de la educación secundaria básica con los que se cierra la enseñanza obligatoria, en esos mismos ámbitos ajenos a lo propiamente histórico la reflexión contrafáctica, en tanto que mirada hacia un pasado diferente destinada a comprender mejor el presente, se ve complementada en dirección opuesta por lo que podríamos denominar «actividades de prospectiva» orientadas a mostrar al alumnado su propia responsabilidad en el presente mediante la reflexión acerca de cómo podría ser el futuro, y así algunos libros de texto correspondientes a estos cursos le ofrecen la posibilidad de especular, en el marco proporcionado por la conexión con los tres temas interdisciplinares, acerca del estado en el que se encontrarán los recursos naturales dentro de un siglo -en relación con el tema "desarrollo sostenible» (bærekraftig utvikling)- y de las amenazas para el futuro de la democracia en 8. curso -con "democracia y ciudadanía" (demokrati og medborgerskap)-, así como de su propia situación a la edad de 27 años en 9. y del acceso a la vida laboral dentro de 50 años en 10.-con «salud pública y destrezas para la vida» (folkehelse og livsmestring)-; vid. respectivamente S. V. Hellerud, S. F. Erdal, I. M. Johnsen, M. Westersjø y O. Hove (2020). Arena 8. Samfunnsfag. Oslo: Aschehoug, bloque tercero En bærekraftig verden («Un mundo sostenible»), tema 12 Ressurser i Norge - hvordan bruke dem bærekraftig? («Recursos en Noruega: ¿cómo utilizarlos de forma sostenible?»), sección Oppgaver («Ejercicios»), apartado Vær kreativ («Sé creativo»), pp. 244-245, ejercicio 5: "Se for deg at du har muligheten til å reise 100 år fram i tid, og at du nå skal rapportere tilbake. Har vi klart å bruke ressursene våre på en bærekraftig måte? Og hva skjedde hvis vi ikke klarte det? Hvordan bruker vi ressursene fra havet, jorda, berggrunnen og vannet om 100 år? Hvilke ressurser er viktige for norsk фkonomi og arbeidsplasser? Skriv et brev eller send en videohilsen tilbake til vår tid» ( «Imagina que tienes la oportunidad de viajar 100 años hacia adelante en el tiempo y que ahora deberías informar. ¿Hemos logrado utilizar nuestros recursos de forma sostenible? ¿Y qué pasó si no lo logramos? ¿Cómo utilizaremos los recursos del mar, la tierra, el lecho rocoso y el agua en 100 años? ¿Qué recursos son importantes para la economía y el empleo noruegos? Escribe una carta o envía un saludo en vídeo a nuestro tiempo»); Heidenreich y Moe (2020), op. cit. n. 30, tema 4 Vi bygger demokrati sammen («Construimos la democracia juntos»), apartado Trusler mot demokratiet («Amenazas a la democracia»), p. 129: "Hva tenker du kan være de viktigste truslene mot de norske demokratiet? (...) Velg et av stikkordene. Hva tror du kan skje hvis denne trusselen vokser til et stort problem? Skriv en framtidsfortelling» («¿Cuáles crees que pueden ser las amenazas más importantes para la democracia noruega? (...) Elige una de las palabras clave. ¿Qué crees que podría suceder si esta amenaza se convierte en un problema importante? Escribe una historia futura»); Nomedal y Bråthen (2007), op. cit. n. 56, tema 4 Arbeidsliv og utdanning 
contemplan la incorporación generalizada de apartados específicos destinados a explicar -a menudo a través de vías particularmente originales- qué es y para qué sirve la historia contrafáctica, una expresión cuyo uso quedará reservado a esta etapa educativa hasta su inclusión en el espacio web que la editorial Gyldendal asocia a la publicación en 2020 del volumen de la serie Relevans destinado al 8. o curso de la enseñanza obligatoria (vid. infra n. 92).

Por lo que se refiere al primer grupo, ya hemos apuntado con anterioridad cómo la editorial Cappelen Damm había publicado manuales escolares individualizados para las áreas de Historia, Geografía y Estudios sociales de la asignatura Samfunnsfag durante los cursos 8.․ 9.ำ y 10.0 de la enseñanza obligatoria en sus series Makt og Menneske (2006) y Nye Makt og Menneske (2014-2016). Dentro de esta última encontramos nuevos ejemplos de la aplicación del razonamiento contrafáctico en ámbitos no propiamente históricos en el marco de esa misma asignatura y entre los volúmenes dedicados específicamente a las ciencias sociales, concretamente en el correspondiente al 9. curso a propósito de la atención sanitaria infantil ${ }^{70}$ y en el de 10. a través de una ucronía personal que persigue suscitar la empatía del propio alumnado en relación con los problemas de niños y jóvenes para acceder a la educación en los países asolados por la guerra ${ }^{71}$. Paralelamente, entre los manuales de esa misma serie correspondientes a la parte histórica de la asignatura, en el volumen destinado a 8. o se pregunta al alumnado acerca de una Europa sin Napoleón y más adelante se le propone la redacción de un texto para el

(«Vida laboral y educación»), sección Tenk selv («Piensa por ti mismo»), cuestión 12, p. 279: «Skriv fortellingen om deg selv som 27-åring. Hva har skjedd siden ungdomsskolen?» («Escribe la historia sobre ti a los 27 años. ¿Qué ha pasado desde la escuela secundaria?»); T. Helland y B. Ingvaldsen (2016). Nye Makt og Menneske 10. Samfunnskunnskap. Oslo: Cappelen Damm, tema 3 Levedyktige samfunn («Sociedades viables»), p. 50, texto del pie de foto de la segunda imagen: «På grunn av rask teknologisk utvikling jobber mange mennesker i yrker som ikke fantes for 30 år siden. Hvordan tror du arbeidslivet er når du skal begynne å jobbe? Hvordan tror du det er om 50 år?» («Debido al rápido desarrollo tecnológico, muchas personas trabajan en ocupaciones que no existían hace 30 años. ¿Cómo crees que es la vida laboral cuando empiezas a trabajar? ¿Cómo crees que será en 50 años?»).

70 T. Helland y B. Ingvaldsen (2015). Nye Makt og Menneske 9. Samfunnskunnskap. Oslo: Cappelen Damm, tema 2 Det aller meste er politikk («La mayoría de las cosas son política!»), sección Politikk angår deg! («iLa política te concierne»), texto del pie de foto de la p. 34: «Helsekontroll av barn har med politikk å gjøre. Hva tror du hadde skjedd hvis dette tilbudet ikke var gratis?» («El control de la salud de los niños tiene que ver con la política. ¿Qué crees que hubiera pasado si esta oferta no fuera gratuita?»).

${ }^{71}$ Helland e Ingvaldsen (2016), op. cit. n. 69, tema 4 "Likegyldigheten er vår verste fiende" (" "La indiferencia es nuestro peor enemigo"»), sección Når krigen gjør barn til soldater ("Cuando la guerra convierte a los niños en soldados»), texto del pie de foto, p. 85: "Hvilke muligheter ser du for deg at du selv ville hatt uten noen form for skolegang? Hva ville du i så fall gjort for å overleve?» («¿Qué oportunidades imaginas que hubieras tenido sin ningún tipo de educación? ¿Qué hubieras hecho entonces para sobrevivir?»). 
periódico escolar sobre una Noruega sin constitución en $1814^{72}$. En el de 9.ㅇ curso de nuevo se plantea una hipótesis alternativa a la historia real para, a continuación, preguntar acerca de las posibles causas que la justificarían cuando, a modo de cuestiones introductorias formuladas inmediatamente después de los títulos correspondientes a los temas 4 y 5 , se interpela al lector "¿Cómo se pudo haber evitado la Segunda Guerra Mundial? ${ }^{73}$. Y en el de 10. se plantean cuestiones de carácter contrafáctico en apartados muy diversos del libro de texto, ya sea para cerrar un apartado de contenidos interrogando acerca de la posibilidad de un ataque nuclear norteamericano contra China durante la Guerra de Corea, como ejercicio final de un tema para plantear la ausencia de una descolonización en África o en el texto de un pie de foto para indagar acerca de un Japón sobre el que no fueron arrojadas las bombas atónicas y que no fue ocupado por Estados Unidos ${ }^{74}$.

En cuanto a los manuales destinados a la educación secundaria superior, el volumen Alle tiders historie Vg2-Vg3 editado ese mismo año por Cappelen Damm inclu-

72 B. Ingvaldsen e I. H. Kristensen (2014). Nye Makt og Menneske 8. Historie. Oslo: Cappelen Damm, tema 2 Opprøri Europa! («iLevantamiento en Europa!»), sección Oppgaver («Ejercicios»), p. 85, ejercicio 6: «Hva tror du ville skjedd dersom Napoleon ikke hadde kommet til makten i Frankrike? Hvordan hadde situasjonen vært i 1815 for a) Frankrike, b) Storbritannia, c) Russland og d) Danmark-Norge» («¿Qué crees que hubiera pasado si Napoleón no hubiera llegado al poder en Francia? ¿Cómo habría sido la situación en 1815 para a) Francia, b) Gran Bretaña, c) Rusia y d) Dinamarca-Noruega?»); ibid., tema 3 Vi ere en Nation, vi med... - Norge på 1800-tallet («Somos una nación, nosotros con... - Noruega en el siglo XIX»), sección Oppgaver («Ejercicios»), p. 127, ejercicio 5: «Hva tror du hadde skjedd dersom Norge ikke hadde fått egen grunnlov i 1814? Skriv en fagtekst om det norske demokratiet til skoleavisa, og pass på at du besvarer spørsmålet med begrunnelser i teksten din» ("¿Qué crees que hubiera sucedido si Noruega no hubiera tenido su propia constitución en 1814? Escribe una redacción sobre la democracia noruega para los periódicos escolares y asegúrate de responder razonadamente a la pregunta en el texto»).

${ }^{73}$ B. Ingvaldsen e I. H. Kristensen (2015). Nye Makt og Menneske 9. Historie. Oslo: Cappelen Damm, pp. 93 (tema 4 Kampen om makten - mellomkrigstiden [«La lucha por el poder: el período de entreguerras»]) y 123 (tema 5 Andre verdenskrig - den dødeligste konflikten i historien [«La Segunda Guerra Mundial: el conflicto más mortifero de la historia»]): «Hvordan kunne andre verdenskrig vært unngått?».

74 B. Ingvaldsen e I. H. Kristensen (2016). Nye Makt og Menneske 10. Historie. Oslo: Cappelen Damm, tema 2 Den kalde krigen ("La Guerra Fría»), apartado Koreakrigen ("Guerra de Corea»), p. 54: «Hva ville ha skjedd om MacArthur hadde brukt atomvåpen mot Kina?» («¿Qué hubiera pasado si MacArthur hubiera usado armas nucleares contra China?»); ibid., ejercicio 10 de la sección Oppgaver («Ejercicios») del tema 3 Avkolonisering og maktkamp («Descolonización y lucha por el poder»), p. 117: «Hva hadde skjedd dersom de tidligere koloniene ikke hadde fått selvstendighet?» («¿Qué hubiera pasado si las antiguas colonias no se hubieran independizado?»); ibid., tema 6 Økonomi og makt («Economía y poder»), apartado Japan («Japón»), texto del pie de foto de la p. 210: "Hva tror du hadde skjedd med Japan dersom USA ikke hadde sluppet atombomber over Japan og okkupert landet?» («¿Qué crees que le habría pasado a Japón si Estados Unidos no hubiera lanzado bombas atómicas sobre Japón y ocupado el país?»). 
ye en el capítulo dedicado a la Europa moderna un apartado breve, pero específico, titulado «¿Qué hubiera pasado si los otomanos hubieran logrado conquistar Viena en 1683 ?» en el que se especula con la posibilidad planteada en el propio título para concluir cuestionando semejante alternativa con argumentos de carácter histórico ${ }^{75}$. Y a propósito de la independencia de Noruega en 1905 un nuevo apartado igualmente breve titulado «¿Pudo haber sucedido la unión?» plantea la posible continuidad de la unión con Suecia, define la historia contrafáctica como «la historia de lo que no sucedió» y termina cuestionando la posibilidad de semejante alternativa ${ }^{76}$.

También en 2013 la editorial Gyldendal publica el ya mencionado volumen Perspektiver. Historie Vg2-Vg3, el cual introduce cuestiones de carácter contrafáctico centradas fundamentalmente en el caso noruego a propósito de una independencia que en 1905 provoca una guerra con Suecia, de la evolución histórica del país a lo largo del siglo XIX y de una Noruega actualmente dominada por el partido nazi de Vidkun Quisling o integrada en la Unión Europea ${ }^{77}$, así como en relación con una Primera

${ }^{75}$ Heum et al. (2013), op. cit. n 33, capítulo 6 Religion og styreformer i Europa («Religión y formas de gobierno en Europa»), apartado Statene i Europa / Det osmanske riket («Los estados de Europa» / «El imperio Otomano»), p. 192, sección Fortid og forklaring («Pasado y explicación»): «Hva hadde skjedd om osmanene hadde klart å erobre Wien i 1683?».

76 Ibid., capítulo 13 Det moderne Norge tar form («La Noruega moderna está tomando forma»), apartado Forhandlingsbrudd og unionsoppløsning («Incumplimiento de negociaciones y disolución de la unión»), p. 361, sección Fortid og forklaring («Pasado y explicación»): «Kunne unionen ha bestått? Hva hadde skjedd hvis svenskene hadde vært mer imøtekommende overfor det norske ønsket om eget konsulatvesen? Ville unionen da bestått, og i så fall hvor lenge? Historien om hva som ikke skjedde, kalles kontrafaktisk historie» ("¿Qué hubiera pasado si los suecos se hubieran mostrado más complacientes con el deseo noruego de tener su propio consulado? ¿Se habría aprobado entonces la unión y, de ser así, por cuánto tiempo?»).

77 Madsen et al. (2013), op. cit. n. 31, capítulo 9 Nasjonsbygging og vekst («Construcción y crecimiento de la nación»), sección Historie nedenfra («Historia desde abajo»), apartado Ut av unionen («Fuera de la unión»), subapartado Et selvstendig, demokratisk Norge («Una Noruega democrática, independiente»), p. 261: «Tenk om det hadde blitt krig med Sverige i 1905» («Imagina si hubiera estallado una guerra con Suecia en 1905»); ibid., capítulo 9, sección Gjøre («Tareas»), p. 262, ejercicio 11: «Velg deg ut en av de store endringene som skjedde i Norge på 1800-tallet. Hvordan kunne Norge sett ut i dag om denne endringen ikke hadde funnet sted? Hva kunne vært annerledes?» («Elige uno de los principales cambios que se produjeron en Noruega en el siglo XIX. ¿Cómo sería Noruega hoy si no se hubiera producido este cambio? ¿Qué podría haber sido diferente?»); ibid., capítulo $15 \mathrm{Ny}$ krig og et vanskelig oppgjør («Nueva guerra y un arreglo difícil»), p. 389, sección Gjøre («Tareas»), ejercicio 9: «Tenk deg at NS har makten i Norge i dag. Hvordan ser samfunnet rundt deg ut?» («Imagínate que el NS tiene el poder en Noruega hoy. ¿Cómo es la sociedad que te rodea?»); ibid., apartado Essay, ensayo del político noruego Jonas Gahr Støre titulado Europa og den lunefulle historien («Europa y la historia caprichosa»), p. 585, sección Gjøre («Tareas»), ejercicio 6: «Skriv deretter en tekst der du drøfter hvordan Norge ville sett ut i dag om vi hadde sagt ja til medlemskap i 1972 eller 1994» («Escribe un texto en el que discutas cómo sería Noruega hoy si hubiéramos acordado ser miembro en 1972 o en 1994»). 
Guerra Mundial sin la participación de los Estados Unidos o incluso sin el atentado de Sarajevo $^{78}$, e igualmente define y explica la utilidad de la reflexión contrafáctica en el ámbito de la historia ${ }^{79}$. Pero la originalidad de esta propuesta reside en el hecho de que casi todos los pasajes citados remiten a la lectura de uno de los textos recogidos en la ya mencionada sección Essay con la que se cierra este manual, titulado de manera muy significativa Historien om det som ikke skjedde, esto es, "La historia de lo que no sucedió» (pp. 586-589). Su autor, Øystein Sørensen, historiador y docente en la Universidad de Oslo, anteriormente ya había publicado un libro con el mismo título en el que repasaba diferentes momentos de la historia universal y de la historia noruega a modo de encrucijadas a partir de las cuales el devenir histórico podría haber sido diferente, desde la batalla de Salamina en 480 a.C. hasta la Segunda Guerra Mundial, pasando por la derrota de la Gran Armada en 1588 o la independencia noruega en $1905^{80}$. Precisamente en la elaboración del ensayo Sørensen toma como punto de partida la primera parte de la introducción de su libro para, a continuación, centrarse en lo que denomina "situaciones históricas abiertas» («åpne historiske situasjoner», pp. 586-587) por cuanto su evolución ofrece posibilidades alternativas tan verosími-

78 Ibid., capítulo 11 Første verdenskrig - den store katastrofen («Primera Guerra Mundial: la gran catástrofe»), apartado Den europeiske krigen blir en verdenskrig («La guerra europea se convierte en una guerra mundial»), sección USA går inn i krigen og gir de allierte overtaket («Estados Unidos entra en guerra y da ventaja a los aliados»), p. 296 (comentario al margen): «Tror du utfallet av første verdenskrig hadde vært annerledes om USA ikke hadde kommet med i krigen?» («¿Crees que el resultado de la Primera Guerra Mundial hubiera sido diferente si Estados Unidos no se hubiera unido a la guerra?»); ibid., p. 301, sección Gjøre («Tareas»), ejercicio 3: "Hva ville skjedd hvis attentatet hadde blitt avverget, tror du?» («¿Qué crees que hubiera pasado si se hubiera evitado el atentado?»).

79 Ibid., capítulo 9 Nasjonsbygging og vekst («Construcción y crecimiento de la nación»), p. 262, sección Gjøre («Tareas»), ejercicio 11: «Hva er kontrafaktisk historieskriving? (...) Hva kan vi lære av kontrafaktisk historieskriving?» («¿Qué es la historiografía contrafáctica? (...) ¿Qué podemos aprender de la historiografía contrafáctica?»).

$80 \varnothing$. Sørensen (2004). Historien om det som ikke skjedde. Kontrafaktisk historie. Oslo: Aschehoug. Precisamente el capítulo dedicado a Salamina (Salamis $480 \mathrm{f} . \mathrm{Kr}$ - persisk seier, ingen europeisk sivilisasjon? ["Salamina 480 a. C. - ¿Victoria persa, sin civilización europea?»]) figura entre los materiales que en su página web la editorial Cappelen Damm ofrece asociados a su libro de texto para la asignatura Historie og filosofi 1 -T. Moum y A. Sævareid (2017). Historie og filosofi 1. Oslo: Cappelen Damm- impartida durante la enseñanza secundaria superior dentro del Programområde for språk, samfunnsfag og økonomi (área programática de Lenguaje, ciencias sociales y economía) que da acceso a la enseñanza universitaria, y allí incorpora además las cuestiones "¿Qué podría haber sucedido si Temístocles hubiera sido expulsado de Atenas?» («Hva kunne ha skjedd dersom Themistokeles hadde blitt utvist fra Aten?») y "¿Conoces situaciones históricas en las que otro resultado podría haber provocado que la historia se hubiera desarrollado de manera completamente diferente?» («Kjenner du til historiske situasjoner der et annet utfall kunne ha ført til at historien hadde utviklet seg helt annerledes?»): https:// historieogfilosofi.cappelendamm.no/kat/aktivitet.html?tid=2149775\&sek=2128472. 
les como diferentes, distinguir seguidamente entre el análisis bien del momento del cambio, bien de la evolución posterior desde ese momento y ya sea desde la investigación histórica o desde el ámbito de la ficción, y finalmente concluir abordando el caso concreto de las consecuencias que para Noruega podrían haberse derivado de una victoria alemana en la Segunda Guerra Mundial. El ensayo se completa con seis actividades, las cuales, como ya apuntamos más arriba, permiten al alumnado profundizar en el tema abordado y figuran asimismo en el espacio que a este manual se dedica en la página web de la editorial ${ }^{81}$.

Finalmente, entre los temas que integran el volumen I ettertid. Lærebok i historie for Vg2 og Vg3 publicado por Aschehoug en 2016 el titulado Cuba i verdens søkelys («Cuba en el centro de atención del mundo», pp. 216-227) se centra en la denominada "crisis de los misiles» de 1962. Y dentro del apartado Hva kunne ha skjedd? ("¿Qué podría haber sucedido?») una de las lecturas en función de las cuales dicho tema se articula consiste en un resumen del ensayo redactado por el historiador estadounidense Robert L. O'Connell The Cuban Missile Crisis: Second Holocaust, presentado como «ejemplo de lo que denominamos historia contrafáctica» mediante la cual "uno intenta imaginar un posible resultado de una situación diferente al que realmente sucedió ${ }^{82}$. Dado que la hipótesis de O’Connell plantea la posibilidad de que la crisis de Cuba hubiese provocado el estallido de una Tercera Guerra Mundial, a continuación se interroga al alumnado acerca de hasta qué punto resulta verosímil dicha alternativa para seguidamente explicar la historia real en el apartado titulado Hva skjedde faktisk? ("¿Qué pasó realmente?») y retomar la cuestión entre los ejercicios de recapitulación planteados al final del capítulo con la pregunta «¿Qué se entiende por historia contrafáctica?»"3.

${ }^{81}$ Recogidas en la sección Gjøre («Tareas»), estas seis actividades se centran en 1) la utilidad de la historia contrafáctica según la plantea Sørensen en el ensayo, 2) las encrucijadas históricas que este autor denomina «situaciones históricas abiertas», 3) la posibilidad de que una hipotética admisión de Hitler en la Academia de Artes de Viena hubiese cambiado la historia de la Alemania de Entreguerras, 4) las consecuencias derivadas de una crisis de los misiles de Cuba resuelta de un modo diferente, 5) la aplicación de la reflexión contrafáctica a un episodio de la vida de cada alumno para construir una ucronía personal y, finalmente, 6) la elaboración por parte de cada alumno de una presentación centrada en un acontecimiento histórico seleccionado entre los mencionados en el ensayo; vid. https://podium.gyldendal.no/perspektiver/elev/ressursbank-ele v?chapter=essay\&content=sorensen-oppgave-1-arbeidsark.

82 Dørum et al. (2016), op. cit. n. 32, p. 222: «Dette er et eksempel på det vi kaller kontrafaktisk historie (...) prøver man å forestille seg et annet mulig utfall av en situasjon enn det som faktisk skjedde». El texto de O'Connel forma parte de la compilación de ensayos contrafácticos editada por Robert Cowley (2003), What Ifs? of American History. Eminent Historians Imagine What Might Have Been. Nueva York: Putnam, pp. 251-272.

83 Ibid., p. 223: "Hvor sannsynlig tror du det er at dette kunne ha skjedd? Hvilke andre hendelsesforløp kan du se for deg?» («¿En qué medida crees probable que esto hubiese sucedido? ¿Qué otro curso de eventos puedes imaginar?»); p. 227: «Hva menes med kontrafaktisk historie?». 
Los libros de texto publicados de acuerdo con la reforma introducida en 2020 no hacen sino confirmar la aplicación del mismo planteamiento. Por una parte en la educación obligatoria la asignatura Samfunnsfag incorpora el recurso al razonamiento contrafáctico en contextos de nuevo ajenos al ámbito propiamente histórico y asociados fundamentalmente a la educación ciudadana y a la participación democrática, si bien desde un momento mucho más temprano. Así se observa en el volumen correspondiente a los cursos 1. y 2. de la serie Arena (2020) cuando en relación con las normas básicas de convivencia vigentes en los escenarios de su vida cotidiana se interroga al alumnado más joven acerca de cómo sería un mundo $\sin$ reglas $^{84}$. Profundizando en esa misma línea y a propósito del sistema democrático el manual de 5. curso de la serie Refleks (2021) se sirve de la reflexión contrafáctica para introducir el tema dedicado a la democracia y, dentro del mismo, para preguntar al alumnado a propósito de la monarquía constitucional y para mostrar el esfuerzo que en una democracia implica dedicar tiempo a abordar los problemas y discutir las opciones ${ }^{85}$, pero también la encontramos en relación con ámbitos interdisciplinares como las nuevas tecnologías, el respeto a las minorías étnicas y el desarrollo sostenible ${ }^{86}$. Y de nuevo en relación con el

${ }^{84}$ Eie y Lien (2020), op. cit. n. 19, tema 1 Ny på skolen («Nuevo en la escuela»), apartado Reglen («Reglas»), p. 12: «Det fins mange ulike regler. Det fins regler på fotballbanen. Det fins regler på skolen. Det fins regler hjemme. (...) Hvordan hadde det vært uten regler?» («Hay muchas reglas diferentes. Hay reglas en el campo de fútbol. Hay reglas en la escuela. Hay reglas en casa. (...) ¿Cómo hubiera sido sin reglas?»).

85 S. Hosteland, T. G. Lie, J. Maliks e Y. Skjæveland (2021). Refleks 5. Samfunnsfag. Oslo: Gyldendal, tema 3 Demokrati («Democracia»), p. 55: "Hvordan hadde det vært hvis du hadde bestemt alt? Hvordan hadde det vært hvis en annen person hadde bestemt alt?» («¿Cómo hubiera sido si tú lo hubieras decidido todo? ¿Cómo hubiera sido si otra persona lo hubiera decidido todo?»); ibid., tema 3, sección Monarkiet («Monarquía»), p. 71, cuestión 2: "Hva tror du hadde skjedd om kongen nektet å signere en lov?» («¿Qué crees que hubiera pasado si el rey se negara a firmar una ley?»); ibid., tema 3, sección Hva kan være vanskelig med demokrati? («¿Qué puede ser difícil de la democracia?»), apartado Demokrati tar tid («La democracia lleva tiempo»), p. 74: «Hva om kongen eller statministeren hadde bestemt alt? Det hadde vært mye enklere» («¿Y si el rey o el primer ministro lo hubieran decidido todo? Habría sido mucho más fácil»).

86 Ibid., tema 5 Vår digitale verden («Nuestro mundo digital»), sección Internett kan brukes til mye («Internet puede ser utilizada para muchas cosas»), p. 109, cuestión 3: «Hvordan hadde det vært hvis vi ikke hadde internett? Hva hadde vært annerledes?» («¿ómo sería si no tuviéramos internet? ¿Qué hubiera sido diferente?»); ibid., tema 6 Hvem er vi? («¿Quiénes somos?»), sección Samene - et urfolk i Norge ("Los Sami: un pueblo indígena en Noruega»), p. 140: «Hvordan hadde det vært hvis det var forbudt å snakke språket ditt på skolen?» («¿Cómo sería si estuviera prohibido hablar tu idioma en la escuela?»); ibid., tema 7 Bærekraftig utvikling («Desarrollo sostenible»), sección Befolkningsvekst og ressursgrunnlag ("Crecimiento de la población y base de recursos»), cuestión 3, p. 157: «Hva ville skjedd hvis alle insektene på jorda forsvant?» («¿Qué pasaría si todos los insectos de la tierra desaparecieran?»). 
ámbito social en el libro de texto correspondiente al 8. curso de la serie Arena (2020) se pregunta al alumnado «¿Y si hubieras vivido en otro lugar del mundo, por ejemplo, en la selva tropical de Nicaragua? ¿Cómo sería entonces tu ciudad natal?", "¿Cómo crees que hubiera sido vivir en una sociedad en la que todos fuesen exactamente iguales?» y finalmente, evocando la ley imperante en la ciudad ficticia de Cardamomo -escenario del libro infantil del autor noruego Thorbjørn Egner Folk og rovere i Kardemomme by (1955)- según la cual «No debes molestar a los demás, debes ser amable y bondadoso. Y, además, puedes hacer lo que quieras», se formula la cuestión "¿Cómo crees que hubiera sido la sociedad si ésta hubiera sido la única ley en Noruega?» ${ }^{87}$.

En este mismo volumen de la serie Arena destinado a 8. curso encontramos aplicaciones específicas de la reflexión contrafáctica al ámbito propiamente histórico, por una parte con una actividad grupal en la que, tras «elegir un evento histórico e investigar con más detalle cómo el evento ha afectado las condiciones de vida en Noruega» -a saber, entre "la gran transformación" [i. e., la modernización de la agricultura durante la segunda mitad del siglo XIX], la llegada de la patata a Noruega, la emigración a Estados Unidos, diversos avances médicos, la instauración del estado del bienestar o la digitalización»-, se planteará un debate sobre «qué podría haber sucedido si el acontecimiento no hubiera tenido lugar ${ }^{88}, y$, por otra, al plantear en relación con las conquistas sociales la pregunta «¿cómo crees que hubiera sido la vida laboral en Noruega hoy si los trabajadores nunca hubieran comenzado a organizarse, protestar y hacer huelga? ${ }^{89}$. Y en el volumen correspondiente al 9. o curso (2020) las cuestiones contrafácticas apuntan al estallido de la Primera Guerra Mundial y al papel desempeñado en el mismo por los asesinatos de Sarajevo, al atentado cometido contra Hitler el 20 de julio de 1944 -con sus consiguientes

${ }^{87}$ Hellerud et al. (2020), op. cit. n. 69, pp. 26 («Men hva om du hadde bodd et helt annet sted i verden, for eksempel i regnskogen i Nicaragua? Hvordan ville hjemstedet ditt sett ut da?»), 27 («Hvordan tror dere det hadde vært å leve i et samfunn der alle var helt like?») y 42 («Hvordan tror du samfunnet hadde vært dersom dette hadde vært den eneste loven i Norge?»).

88 Ibid., primera parte Individ og samfunn («Individuo y sociedad»), tema 4 Norge fra fattigdom til velstand («Noruega: de la pobreza a la prosperidad»), sección Oppgaver («Ejercicios»), p. 86, apartado Utforsk («Explorar»), ejercicio 5: «Diskuter hva som kunne skjedd dersom hendelsen ikke hadde skjedd».

89 Ibid., segunda parte Demokrati og deltakelse («Democracia y participación»), tema 8 Streik og samarbeid - fra kamp til rettigheter i arbeidslivet ("Huelgas y cooperación: de la lucha a los derechos en la vida laboral»), p. 157, apartado Bedre rettigheter for arbeiderne («Mejores derechos para los trabajadores»), entradilla Reflekter («Refexionar»): "Hvordan tror du arbeidslivet ville ha vært i Norge i dag om arbeiderne aldri hadde begynt å organisere seg, protestere og streike?». 
implicaciones éticas- y a una Noruega carente de la legislación que el Parlamento aprobó en 2005 sobre los derechos humanos ${ }^{90}$.

Paralelamente, la editorial Gyldendal está publicando en la actualidad la serie Relevans, que en el volumen destinado a 8. curso (2020) interroga al alumnado en relación con las revoluciones americana y francesa ${ }^{91}$. Precisamente en relación con los mismos temas la página web de la editorial recoge sendos artículos que plantean la reflexión contrafáctica en términos idénticos en el caso americano, mientras que en el francés incorpora además una explicación básica acerca de qué es la historia contrafáctica para remitir a continuación al capítulo correspondiente del manual ${ }^{92}$.

90 S. V. Hellerud, S. F. Erdal, I. M. Johnsen y M. Westersjø (2020). Arena 9. Samfunnsfag. Oslo: Aschehoug, tema 5 Første verdenskrig - årsaker og konsekvenser («Primera Guerra Mundial: causas y consecuencias»), apartado Krigens gang ("El curso de la guerra»), sección Første verdenskrig 1914-1918 ("La Primera Guerra Mundial 1914-1918»), p. 114: "Kan du tenke deg hva som kunne vært gjort for å unngå krigen? (...) Hva tror du ville skjedd hvis denne hendelsen ikke hadde funnet sted?» («¿Te imaginas lo que se podría haber hecho para evitar la guerra? (...) ¿Qué crees que hubiera pasado si este incidente no hubiera ocurrido?»); ibid., tema 6 Mot en ny storkrig - mellomkrigstid og annen verdenskrig («Hacia una nueva gran guerra: entreguerras y la Segunda Guerra Mundial»), sección Oppgaver («Ejercicios»), p. 148: «Hvis attentatet hadde lyktes, kunne historien sett annerledes ut. Kanskje ville krigen blitt avsluttet tidligere, og tusenvis av menneskeliv kunne vært spart. Hvilken holdning har du til attentatmennene? Er det riktig å hedre dem og arrangere minnestund knyttet til attentatfors $\varnothing$ ket?» («Si el ataque hubiera tenido éxito, la historia podría haber sido diferente. Quizá la guerra habría terminado antes y se podrían haber salvado miles de vidas. ¿Cuál es tu actitud hacia los asesinos? ¿Es correcto honrarlos y organizar un servicio conmemorativo en relación con el intento de asesinato?»); ibid., tema 8 Mot en bedre verden? - FN og internasjonalt samarbeid ("¿Hacia un mundo mejor? - La ONU y la cooperación internacional»), apartado Menneskerettigheter i dag («Los derechos humanos hoy»), sección Hva med Norge? («¿Qué pasa en Noruega?»), p. 182: «Tror du det hadde vært annerledes å bo i Norge hvis vi ikke hadde hatt en menneskerettslov?» («¿Crees que hubiera sido diferente vivir en Noruega si no hubiéramos tenido una ley de derechos humanos?»).

${ }^{91}$ Heidenreich y Moe (2020), op. cit. n. 30, tema 3 Kamp for rettigheter («Lucha por los derechos»), sección Den amerikanske revolusjonen («La revolución americana»), p. 81, apartado Spørsmål («Preguntas»), cuestión 3: "Hva tror du hadde vært annerledes i USA i dag, hvis det ikke hadde vært en revolusjon der i 1776?» («¿Qué crees que hubiera sido diferente en los Estados Unidos hoy si no hubiera tenido lugar una revolución allí en 1776?»); ibid., tema 3, sección Den franske revolusjonen («La revolución francesa»), p. 96, apartado Kapitteloppgaver («Ejercicios del capítulo»), ejercicio 4: «Hva om det ikke hadde vært revolusjon i Frankrike?: a) Hvordan tror du samfunnet ville ha vært i dag hvis det ikke hadde vært revolusjon i Frankrike? Skriv ned stikkord. b) Skriv en fortelling eller en annen type tekst om hvordan du tror et slikt fantasisamfunn hadde vært» («¿Y si no hubiera tenido lugar una revolución en Francia?: a) ¿Cómo crees que hubiera sido la sociedad hoy si no hubiera tenido lugar una revolución en Francia? Anota las palabras clave. b) Escribe una historia u otro tipo de texto sobre cómo crees que hubiera sido una sociedad imaginaria»).

${ }^{92}$ Hvordan ble USA til USA? - Den amerikanske revolusjonen («¿Cómo se convirtió Estados Unidos en Estados Unidos? - La revolución americana»: https://www.gyldendal.no/artikler/ 
En cuanto a los libros de texto de historia correspondientes a la educación secundaria superior, aun cuando durante el presente curso 2020/2021 la nueva reforma todavía no se ha aplicado a la asignatura Historie impartida en los cursos Vg2 y Vg3, sin embargo hemos apuntado más arriba que ya disponemos del volumen Alle tiders Historie editado para ambos cursos por Cappelen Damm (2020), el cual evidencia en este punto una marcada continuidad respecto de su antecesor publicado en 2013 por cuanto volvemos a encontrar la reflexión contrafáctica aplicada a los mismos episodios históricos, si bien introduciendo un mayor grado de complejidad. Así, en el caso del segundo sitio de Viena por los turcos resultan novedosos no tanto el título del apartado «¿Y si los otomanos hubieran logrado conquistar Viena en 1683 ? ${ }^{93}$, sino sobre todo el texto inicial que explica en qué consiste la historia contrafáctica ${ }^{94}$ y la interpelación final «¿Qué crees que hubiera pasado si Viena hubiera caído en 1683 ?» a la que se asocia la actividad «Realiza una búsqueda sobre la historia contrafáctica y explora una o más preguntas ${ }^{95}$. En relación con

relevans-den-amerikanske-revolusjonen/). Hva om det ikke hadde vært revolusjon i Frankrike? («¿Y si no hubiera tenido lugar una revolución en Francia?», https://www.gyldendal.no/artikler/ relevans-den-franske-revolusjonen/): «Tenk deg at historiske hendelser ikke hadde skjedd eller at de hadde endt opp helt annerledes enn de gjorde. Det kalles for kontrafaktisk historiefortelling» ( «Imagínate que los acontecimientos históricos no hubieran sucedido o que hubieran resultado de un modo completamente diferente a como lo hicieron. Eso se denomina narración contrafáctica»). En el mismo volumen se introduce una última cuestión de tipo condicional -si bien no contrafáctico- cuando, a propósito de la cesión del territorio de Noruega a Suecia que Dinamarca se ve obligada a aceptar tras la derrota de su aliado Napoleón en 1814, se pregunta al alumnado «Hva tror du ville ha skjedd hvis herskere prøvde å fordele land mellom seg på denne måten i dag?» («¿Qué crees que sucedería si los gobernantes intentasen dividir el territorio entre ellos hoy de esta manera?»), ibid., tema 4 Vi bygger demokrati sammen («Construimos la democracia juntos»), sección Storkrigen. Som gjorde Norge til et selvstendig land («La Gran Guerra. Lo que convirtió a Noruega en un país independiente»), p. 119, cuestión 2.

${ }^{93}$ Heum et al. (2020), op. cit. n. 33, capítulo 6 Religion og styreformer i Europa («Religión y formas de gobierno en Europa»), apartado Statene i Europa / Det osmanske riket («Los estados de Europa» / «El imperio Otomano»), p. 206, sección Perspektiver («Perspectivas»): «Hva om osmanene hadde klart å erobre Wien i 1683?».

94 Ibid.: «Mye av historiefaget dreier seg om å forklare hvorfor noe skjedde. Når hendelser framstilles som årsak til en seinere utvikling, betyr det samtidig at hvis den første hendelsen ikke hadde inntruffet, så kunne utviklingen blitt annerledes. Kontrafaktisk historieskrivning viser at historien var full av muligheter. Kontrafaktisk historie dreier seg om det som kunne ha skjedd, men som ikke skjedde» («Gran parte de la asignatura de historia trata de explicar por qué sucedió algo. Cuando los eventos se presentan como la causa de un desarrollo posterior, también significa que si el primer evento no hubiera ocurrido, el desarrollo podría haber sido diferente. La escritura de la historia contrafáctica muestra que la historia estaba llena de posibilidades. La historia contrafáctica trata de lo que pudo haber sucedido, pero que no sucedió»).

95 Ibid.: «Hva tror du hadde skjedd om Wien hadde falt i 1683 ? Gjør et søk på kontrafaktisk historie og utforsk ett eller flere spørsmål». 
la independencia de Noruega en 1905 se plantea la posible continuidad de la unión con Suecia bajo los mismos interrogantes que en la edición anterior, se define la historia contrafáctica en los mismos términos y únicamente se añade como colofón del apartado la pregunta "¿Crees que la unión podría haber sobrevivido hoy?» ${ }^{96}$. Y como novedad encontramos un pasaje sobre la constitución noruega de 1814 que en la edición de 2013 no incluía ninguna propuesta relacionada con el razonamiento contrafáctico y que, a propósito del siglo de las Luces y de las revoluciones, ahora en la de 2020 pregunta directamente al alumnado «¿Qué crees que habría sucedido si Noruega no hubiera tenido una constitución libre en 1814? ¿Habríamos sido suecos o daneses en la actualidad? $\wedge^{97}$.

Finalmente cabe destacar cómo, más allá de los libros de texto, encontramos asimismo materiales didácticos relacionados con la historia contrafáctica destinados a la enseñanza obligatoria y a la educación secundaria superior en plataformas educativas on-line designadas con el término læringsarena, "espacios de aprendizaje» virtuales en continuo crecimiento que ofrecen recursos multimedia en abierto tanto al alumnado que cursa dichas etapas como a los profesionales que imparten su docencia en ellas.

En relación con la enseñanza obligatoria la página web de Nettskulen (https:// nettskulen.no/) alberga recursos y actividades concebidas para los cursos 5. a 10. y distribuidas por áreas coincidentes con las asignaturas impartidas durante los mismos. Así, en la sección Samfunnsfag encontramos cinco de ellas publicadas en fechas muy recientes por Morten Hetland, responsable de esta página web, y asociadas de manera explícita al objetivo competencial de la asignatura homónima recogido en la reforma de 2020 en el que se plantea el recurso a la reflexión contrafáctica (vid. supra, n. 40), concretamente a propósito de los escenarios históricos correspondientes a las revoluciones americana y francesa, el ascenso de Hitler, la crisis de los misiles de Cuba y el Muro de Berlín, tema este último entre cuyos «ejercicios de inmersión» (fordjupingsoppgåver) figura además la pregunta «¿Cómo podría haberse desarrollado de manera diferente Alemania si el país no se hubiera dividido entre el oeste y el este durante 45 años? $\|^{98}$.

96 Ibid., capítulo 11 Det moderne Norge tar form («La Noruega moderna está tomando forma»), apartado Demokratisering («Democratización»), p. 409, sección Fortid og forklaring («Pasado y explicación»): «Tror du unionen kunne ha bestått i dag?».

97 Ibid., capítulo 8 Opplysningstid, revolusjoner og ideologier («La era de las luces, revoluciones e ideologías»), apartado 1814: En norsk revolusjon? («1814: ¿una revolución noruega?»), p. 289, sección Historiebevissthet («Conciencia histórica»): "Hva tror du hadde skjedd om Norge ikke hadde fått en fri grunnlov i 1814. Hadde vi da vært svenske eller danske nå?».

98 Den amerikanske revolusjonen ("La revolución americana», 28 de marzo de 2021): https://nettskulen.no/den-amerikanske-revolusjonen/. Den franske revolusjonen («La revolución francesa», 28 de marzo de 2021): https://nettskulen.no/den-franske-revolusjonen/. Hitler sin 
Más ambicioso resulta el proyecto para educación secundaria superior representado por la Nasjonal Digital Læringsarena (NDLA: https://ndla.no/). Impulsada en 2006 por el Ministerio de Educación e Investigación y gestionada por una agrupación de condados, NDLA reúne textos, imágenes, grabaciones de vídeo y de audio, enlaces, tareas y herramientas de evaluación hasta actuar, en la práctica, como sustituto digital del libro de texto por cuanto se propone cubrir todos los objetivos competenciales establecidos en el plan de estudios e incluso ir más allá al posibilitar el intercambio de materiales, la escritura colaborativa y la incorporación de comentarios (Knutsen, 2017, pp. 119-129). Esta página web ofrece materiales asociados con la impartición de la asignatura Historie durante el curso Vg3 en el marco del área "Sociedad y seres humanos en el tiempo» (Samfunn og mennesker $i$ tid) correspondiente a la estructura establecida por la reforma de 2006 -pues, como ya se ha apuntado anteriormente, será a partir del curso 2021/2022 cuando la reforma de 2020 se aplique a la enseñanza de la historia durante la educación secundaria superior- tanto dentro del programa de Especialización de estudios (SF Vg3) como durante el curso puente que desde la formación profesional permite acceder a la educación universitaria (PB Vg3).

Un primer grupo de materiales figura asociado al tema de la Primera Guerra Mundial, entre cuyos objetivos figura explícitamente que el alumno sea capaz de "discutir la historia contrafáctica y diferentes puntos de vista de la historia sobre la Primera Guerra Mundial ${ }^{99}$. En primer lugar con un artículo dotado de un enlace a un texto de $\varnothing$ ystein Sørensen publicado en la página web de la corporación de radiodifusión pública de Noruega (NRK) y en el que este autor plantea la posibilidad de una rápida victoria alemana sobre Francia y, en consecuencia, de un siglo Xx mucho más pacífico para Europa y para el mundo (Sørensen, 2014) ${ }^{100}$. Y seguidamente en la sección Oppgaver og aktiviteter («Ejercicios y actividades») con la propuesta

veg til makta («El camino de Hitler hacia el poder», 28 de marzo de 2021): https://nettskulen. no/hitler-sin-veg-til-makta/. Cubakrisa («La crisis de Cuba», 28 de marzo de 2021): https:// nettskulen.no/cubakrisa/. Berlinmuren («El Muro de Berlín», 10 de enero de 2021: "Korleis kunne Tyskland ha utvikla seg annleis, dersom landet ikkje hadde vore delt mellom vest og aust $\mathrm{i}$ 45 år?»): https://nettskulen.no/berlinmuren/.

99 Første verdenskrig - avslutning og oppgjør. Introduksjon: "Kunne drøfte kontrafaktisk historie og ulike historiesyn om første verdenskrig» (https://ndla.no/subject:9/topic:1:182163/ topic:1:184957/topic:1:168025/resource:1:185169?filters=urn:filter:e0aOfaa8-cefd-481f-bf79b45ad4d7c5e7).

100 J. Saakvitne y S. U. Larsen (Senter for nye medier, Høgskolen i Bergen), Kontrafaktisk historie («Historia contrafáctica», 3 de enero de 2018): https://ndla. no/subject:9/topic:1:182163/ topic:1:184957/topic:1:168025/resource:1:168714?filters=urn:filter:9132d125-4d8f-41a6b61d-77741662d5a9. El mismo artículo de Sørensen figura como recurso complementario del libro de texto de E. Arnesen (ed.) (2010). Portal. Påbygging: verdenshistorie og Norgeshistorie vg3. Oslo: Fagbokforlaget, en el apartado que esta editorial le dedica en su página web: http:// portal.fagbokforlaget.no/menypunkt.cfm?id=76-286-1\& mpid=1405,7744. 
de una serie de tareas consistentes en 1) resumir los argumentos que permiten a este autor defender semejante hipótesis y responder a las cuestiones «¿Y si Alemania / Austria-Hungría hubieran ganado la Primera Guerra Mundial? ¿Qué Europa habríamos tenido hoy? ¿Nunca habrían surgido el nazismo y el comunismo? ¿Tendríamos una Europa más pacífica?»; 2) redactar un texto sobre «lo que podría haberle sucedido a Hitler y al nazismo si los alemanes hubieran ganado la Primera Guerra Mundial» para así indagar sobre las razones del ascenso nazi en la historia real y plantear otras alternativas -incluso tan a largo plazo como, por ejemplo, el nacimiento de la Unión Europea-; y finalmente 3) discutir si la historia contrafáctica «es un juego mental o algo de lo que podamos aprender» ${ }^{101}$.

A su vez, el segundo grupo de materiales se halla vinculado al tema de la Segunda Guerra Mundial. Por una parte encontramos un artículo con toda una batería de preguntas acerca de alternativas en las que o bien Hitler no existe, o bien Alemania derrota a Gran Bretaña y a la Unión Soviética, el atentado de 1944 contra Hitler tiene éxito o el desembarco de Normandía fracasa, todo ello para mostrar que "lo emocionante» de «investigar y encontrar respuestas alternativas a estas preguntas» requiere "conocer las razones de lo que realmente sucedió y ser capaz de evaluar las posibilidades de cursos alternativos de eventos ${ }^{102}$. Y por otra contamos con dos tipos de tareas: una, más sencilla, limitada a la simple formulación de la pregunta "¿Qué hubiera pasado si los americanos no hubieran usado las bombas atómicas? » ${ }^{103}$; y otra, más compleja y variada, centrada en la valoración de diferen-

101 J. Saakvitne y S. U. Larsen (Senter for nye medier, Høgskolen i Bergen), Hva om Tyskland hadde vunnet første verdenskrig? («¿Y si Alemania hubiera ganado la Primera Guerra Mundial?», 7 de marzo de 2017: https://ndla.no/nn/subject:9/topic:1:182163/topic:1:184957/ topic:1:168025/resource:1:168718?filters=urn:filter:e0a0faa8-cefd-481f-bf79-b45ad4d7c5e7): 1) «Hva om Tyskland/Østerrike-Ungarn hadde vunnet første verdenskrig? Hvilket Europa hadde vi da hatt i dag? Ville nazismen og kommunismen aldri oppstått? Ville vi fått et fredeligere Europa?»; 2) «hva som kunne ha skjedd med Hitler og nazismen om tyskerne hadde vunnet første verdenskrig (...) Diskuter ulike scenarioer, og se på mulighetene for andre utfall enn dem som faktisk skjedde. Hva med langsiktige virkninger som for eksempel EU?»; 3) «Diskuter: Er kontrafaktisk historiesyn bare lek med tanker eller noe vi kan lære av?».

102 J. Saakvitne y S. U. Larsen (Senter for nye medier, Høgskolen i Bergen), Kontrafaktisk historiefortelling om andre verdenskrig («Narración contrafáctica sobre la Segunda Guerra Mundial», 2 de noviembre de 2017: https://ndla.no/nn/subject:9/topic:1:182163/ topic:1:184957/topic:1:168758/resource:1:169220?filters=urn:filter:9132d125-4d8f-41a6b61d-77741662d5a9): "Det som er spennende, er å undersøke og finne alternative svar på disse spørsmålene. Da må du kjenne årsakene til det som faktisk skjedde, og kunne vurdere mulighetene for alternative forl $\emptyset p$ av begivenhetene».

103 J. Saakvitne y S. U. Larsen (Senter for nye medier, Høgskolen i Bergen), Atombombene («Las bombas atómicas», 7 de marzo de 2017: https://ndla.no/nn/subject:9/topic:1:182163/ topic:1:184957/topic:1:168758/resource:1:169019?filters=urn:filter:9132d125-4d8f41a6-b61d-77741662d5a9): "Hva hadde skjedd om amerikanerne ikke hadde benyttet atombombene?». 
tes aproximaciones contrafácticas de carácter ficcional al tema de una victoria del Eje durante la Segunda Guerra Mundial generadas en el marco de la cultura popular contemporánea, mediante el recurso a sendos enlaces a una entrevista a Philip Roth en relación con su novela The Plot Against America (2004), a una reseña de la novela 1957 del autor noruego Jon Ewo (2014) y al tráiler de la primera temporada de la serie televisiva The Man in the High Castle (Amazon Studios, 2015, inspirada en la novela homónima de Philip K. Dick publicada en 1962), así como al mapa del territorio de los Estados Unidos repartido entre las potencias victoriosas del Eje en el mundo alternativo en el que se desarrolla el argumento de dicha serie, aproximaciones a las que el usuario puede añadir otra de elaboración propia, pero siempre con la finalidad de reflexionar acerca de hasta qué punto resulta históricamente probable la evolución de la sociedad que se presenta en ellas ${ }^{104}$.

\section{CONCLUSIÓN}

El caso noruego constituye un modelo por lo que implica en tanto que reconocimiento oficial del valor didáctico que encierra la historia contrafáctica al incluir de manera explícita este tipo de reflexión en el texto que orienta el proceso de enseñanza y aprendizaje como un aspecto de las competencias que el alumno debe adquirir a lo largo del mismo con la finalidad última de desarrollar el pensamiento crítico y comprender las nociones de causalidad y, particularmente, de multicausalidad. La sustitución de los planes de estudios derivados de la reforma de 2006 por los que en la actualidad se están introduciendo como consecuencia de la implantación de la nueva reforma de 2020 incorpora evidentes novedades, pero establece asimismo una continuidad tanto por lo que se refiere a la finalidad que atribuye a la enseñanza de la historia como en relativo a la presencia del razonamiento contrafáctico entre los objetivos competenciales del currículo educativo que debe alcanzar el alumnado que cursa la asignatura interdisciplinar de Estudios sociales durante los tres años de la educación secundaria básica -los tres últimos de la enseñanza obligatoria- y el que cursa la asignatura específica de Historia durante los cursos segundo y tercero de la educación secundaria superior.

104 J. Saakvitne y S. U. Larsen (Senter for nye medier, Høgskolen i Bergen), Kontrafaktiske problemstillinger («Problemas contrafácticos», 6 de septiembre de 2018: https://ndla.no/nn/ subject:9/topic:1:182163/topic:1:184957/topic:1:168758/resource:1:169446?filters=urn:filte r:9132d125-4d8f-41a6-b61d-77741662d5a9): «Ta for deg en eller flere av disse kontrafaktiske problemstillingene, eller lag din egen, som du utvikler og viser mulige konsekvenser av. Vurder ideen som ligger bak. Hvor sannsynlig er den samfunnsutviklingen som beskrives?» («Considera uno o más de estos problemas hipotéticos o elabora uno propio que desarrolle y muestre las posibles consecuencias. Considera la idea subyacente. ¿Cuán probable resulta la evolución de la sociedad que se discute aquí?»). 
Ello se traduce en la incorporación de la reflexión contrafáctica como recurso didáctico a los materiales curriculares, fundamentalmente a los manuales escolares asociados a la impartición de cada una de esas dos asignaturas. Y si bien en ellos encontramos esta fórmula aplicada a cuestiones vinculadas con la vida en sociedad, con la participación democrática y con el desarrollo sostenible -los tres temas transversales en función de los cuales se articulan los nuevos planes de estudios-, sin embargo predomina, con mucho, en el ámbito de la historia, plasmada en propuestas asociadas a episodios que actúan a modo encrucijadas a partir de las cuales ciertamente la historia podría haber sido diferente, sobre todo como resultado de la adopción de otras decisiones por parte de los individuos que los protagonizaron. Tales propuestas se ubican casi exclusivamente en el período correspondiente a la edad contemporánea y particularmente en acontecimientos de especial relevancia para la historia de Noruega -la constitución de 1814, la independencia en 1905, la Segunda Guerra Mundial, la consecución del estado del bienestar durante la segunda mitad del siglo $x x$ - por tratarse del marco cronológico y espacial más atractivo para el alumnado dada su mayor proximidad a su propio contexto histórico, social y cultural y, en consecuencia, más útil para despertar su interés, por oposición a épocas más lejanas de cuyo devenir alternativo sería mucho más difícil deducir unos resultados significativos para el presente en el que ese mismo alumnado se desenvuelve. Y lo hacen tomando como punto de partida los conocimientos adquiridos en cada tema acerca de la historia de lo que realmente sucedió y a través de actividades centradas en la posibilidad de contemplar escenarios alternativos históricamente verosímiles y de reflexionar acerca de las causas que, bien por acción o por omisión, los podrían haber motivado, así como de las consecuencias derivadas de los mismos y de la utilidad misma de la historia contrafáctica. Estas actividades alcanzan desde la formulación de una simple pregunta dirigida al alumnado y destinada a ser contestada individualmente hasta el diseño de este tipo de cuestiones por parte del mismo -ya sea libre o guiado de acuerdo con fórmulas prediseñadas-, en uno y otro caso bien de manera individual, por parejas o por grupos (incluso rotando sus integrantes) y a menudo con la finalidad última de suscitar un debate dentro del aula, pero incluyen igualmente la redacción de ensayos -incluso para publicar en el periódico escolar-, la elaboración de resúmenes o la deducción de palabras clave mediante el recurso a fuentes históricas primarias y secundarias e incluso a productos de carácter ficcional -unas y otros facilitados en el propio texto o a través de enlaces web-. Bajo fórmulas tales como "qué crees que hubiera sucedido», "usa tu imaginación», «imagina» o "fantasea», unas y otras se ubican fundamentalmente en preguntas asociadas al texto explicativo tanto en secciones específicas situadas al margen como en otras dispuestas al final del apartado o incluso del tema junto a otros ejercicios destinados a la recapitulación de los contenidos y a la consolidación de los aprendizajes realizados, pero también en subtítulos localizados en la primera página del tema e incluso en pies de foto. 
Ciertamente, no podemos negar la existencia de cierta «sensibilidad especulativa» que, entre otros factores -la crisis de las ideologías en Occidente, la evolución de la ciencia moderna, la revolución de las TIC, la cultura del ocio y la influencia del pensamiento posmoderno-, contribuiría a explicar el éxito de la historia contrafáctica desde fechas recientes tanto en el ámbito de la investigación histórica como en el de la cultura popular contemporánea (Rosenfeld, 2005, pp. 5-11). Sin embargo, tal vez la «juventud» de Noruega como país independiente tan solo desde 1905 y tras siglos de subordinación respecto a sus vecinos -cuestión directamente vinculada con la definición de la propia identidad nacional- haya influido en tanto que factor determinante a la hora de reconocer la importancia de la contingencia histórica -un elemento íntimamente ligado a la práctica de la reflexión contrafáctica en este ámbito- hasta el punto de incorporarla entre los objetivos que el sistema educativo establece para la formación de sus ciudadanos. Un fenómeno, en suma, a propósito del cual cabe recordar las reflexiones de Fredrik W. Thue (2019, p. 187) cuando apunta que la progresiva sustitución de la enseñanza de una historia de los acontecimientos y de los procesos por otra de la que el alumnado debe extraer aprendizajes que le sirvan para desenvolverse en el mundo que le rodea -un mundo en el que el conocimiento se torna obsoleto a un ritmo cada vez más rápido- no hace sino reflejar hasta qué punto en este cometido se erige como recurso fundamental la capacidad del individuo para orientarse y actuar en un presente siempre nuevo y cuando tanto el pasado como el futuro se han vuelto radicalmente contingentes y ya no sirven como guía.

\section{REFERENCIAS BIBLIOGRÁFICAS}

Ask, L. T. V. (2009). Hvordan sikter lærebøker i historie mot å utvikle historiebevissthet. En sammenligning av lærebøker i den videregående skole fra 1976-2007 [Cómo los libros de texto de historia tienen como objetivo desarrollar la conciencia histórica. Una comparación de los libros de texto en la escuela secundaria superior 1976-2007]. Masteroppgave i historiedidaktikk (Det humanistiske fakultet - Universitetet i Stavanger). Recuperado el 29 de marzo de 2021, de http://hdl.handle.net/11250/185350

Beavers, S. M. (2020). The Informal Learning of History with Digital Games. Tesis Doctoral (Institute of Educational Technology - The Open University). https:// doi.org/10.21954/ou.ro.0001111f

Bjerke-Hagen, M. (2011). Kontrafaktisk historie i undervisning: nyttig undervisningsmetode eller rent tidsfordriv? [Historia contrafáctica 
en la enseñanza: ¿método de enseñanza útil o puro pasatiempo?]. Mastergradsoppgave i historie (Fakultet for humaniora, samfunnsvitenskap og lærerutdanning - Universitetet i Troms $\varnothing$ ). http://munin.uit.no/ handle/10037/3489

Bratholm, B. (2001). Godkjenningsordningen for lærebøker 1889-2001. En historisk gjennomgang [El sistema de aprobación de los libros de texto 1889-2001. Una reseña histórica]. En S. Selander y D. Skjelbred (eds.), Fokus på pedagogiske tekster, 5. Tønsberg: Høgskolen i Vestfold. http://www-bib.hive.no/tekster/ hveskrift/notat/2001-05/not5-2001-02.html

Buxton, E. (2010). Fog over channel; continent accesible? Year 8 use counterfactual reasoning to explore place and social upheaval in eighteenth-century France and Britain. Teaching History, 140, pp. 4-15.

Buxton, E. (2016). Historical Causation: Counterfactual Reasoning and the power of Comparison. En Ch. Counsell, K. Burn y A. Chapman (eds.), MasterClass in History Education. Transforming Teaching and Learning (pp. 23-42). Londres Nueva York: Bloomsbury. https://doi.org/10.5040/9781474285476.ch-002

Carroll, J. E. (2018). Couching counterfactuals in knowledge when explaining the Salem witch trials with Year 13. Teaching History, 172, pp. 18-29.

Cercadillo, L., Chapman, A. y Lee, P. (2017). Organizing the Past: Historical Accounts, Significance and Unknown Ontologies. En M. Carretero et al. (eds.), Palgrave Handbook of Research in Historical Culture and Education (pp. 529-552). Londres: Palgrave Macmillan. https://doi.org/10.1057/978-1-137-52908-4_28

Clark, J. y Nye, A. (2018). The Three Contexts of Writing About History Teaching. En Ead. (eds.), Teaching the Discipline of History in an Age of Standards (pp. 1-19). Singapur: Springer. https://doi.org/10.1007/978-981-13-0047-9_1

Clausen Waage, T. L. (2019). Spillifiseringen av den første verdenskrig i FPS-spill, og hva det kan bety for spillernes historiebevissthet [La jugabilidad de la Primera Guerra Mundial en los juegos de FPS y lo que puede significar para la conciencia histórica de los jugadores]. Masteroppgave i historiedidaktikk (Fakultet for utdanningsvitenskap og humaniora - Universitetet i Stavanger). http://hdl. handle.net/11250/2601403

Cooper, H. (2013). Why must teaching and learning in History be creative? En Ead. (ed.), Teaching History Creatively (pp. 3-18). Londres - Nueva York: Routledge. 
Delgado-Algarra, E. J. y Pelegrín Campo, J. (2018). El manga como recurso didáctico en la enseñanza de la Historia: el caso de Adolf, de Osamu Tezuka. En D. Verdú, C. Guerrero y J. L. Villa (eds.), Pensamiento histórico y competencias sociales y cívicas en Ciencias Sociales (pp. 205-217). Murcia: Editum. Ediciones de la Universidad de Murcia. http://libros.um.es/editum/catalog/ view/2031/2711/2651-1

Deluermoz, Q., y Singaravélou, P. (2016). Pour une histoire des possibles. París: Éditions du Seuil.

Demandt, A. (1993). History That Never Happened: A Treatise on the Question, What Would Have Happened If ...? Jefferson: McFarland.

Demandt, A. (2002). Kontrafaktische Geschichte. En S. Jordan (ed.), Lexikon der Geschichtswissenschaft. Hundert Grundbegriffe (s.v., pp. 190-191). Stuttgart: Reclam Verlag.

Demandt, A. (2011). Ungeschehene Geschichte. Ein Traktat über die Frage: Was wäre geschehen, wenn...? Gotinga: Vandenhoeck \& Ruprecht GmbH \& Co. KG.

Domínguez Castillo, J. (2015). Pensamiento histórico y evaluación de competencias. Barcelona: Graó.

Domínguez Castillo, J. (2016). Enseñar y evaluar el pensamiento histórico: competencias, conceptos y destrezas cognitivas. Íber. Didáctica de las Ciencias Sociales, Geografía e Historia, 82, pp. 43-49.

Domínguez Castillo, J., Arias, L., Sánchez, R., Egea, A. y García, Fco. J. (2016). Cómo evaluar el pensamiento histórico en la ESO: primeros resultados de una prueba piloto. En R. López Facal (ed.), Ciencias sociales, educación y futuro. Investigaciones en didáctica de las ciencias sociales (pp. 176-187). Santiago de Compostela: Red 14 - Universidad de Santiago de Compostela. http://docs. wixstatic.com/ugd/79b507_b442e42c951f4ba68cd44babe07b03ee.pdf

Dumas, W. (1969). Speculative Reconstruction of History: A New Perspective on an Old Idea. Social Education, 33(1), pp. 54-55.

Eurydice (2008). Autonomía y responsabilidades del profesorado en Europa. Bruselas: Eurydice. https://www.sel-gipes.com/uploads/1/2/3/3/12332890/2008_ eurydice_-_levels_of_autonomy_and_responsibilities_of_teachers_in_ europe_sp.pdf 
Eurydice (2010). History in the curriculum. Slough: Eurydice at NFER. http://www. herrflynn.com/htai/docs/2012_docs/2012_eurydice_stats_history_europe_ schools.pdf

Eurydice (2021). Norway. Bruselas: Eurydice. https://eacea.ec.europa.eu/nationalpolicies/eurydice/content/norway_en

Evensen, A. (2018). Rollespill som metodisk verktøy i samfunnsfag - En studie om abstrakte og komplekse samfunnsfaglige begreper og sammenhenger i rollespill [El juego de rol como herramienta metodológica en ciencias sociales: un estudio de conceptos y contextos abstractos y complejos de las ciencias sociales en el juego de rol]. Masteroppgave i skolerettet utdanningsvitenskap med fordypning i samfunnsfag (Fakultetet for lærerutdanning og internasjonale studier OsloMet - storbyuniversitetet). https://oda.oslomet.no/handle/10642/6190

Feliu Torruella, M.a y Hernàndez Cardona, F. X. (2011). 12 ideas clave. Enseñar y aprender historia. Barcelona: Graó.

Ferguson, N. (1998). Historia virtual: hacia una teoría caótica del pasado. En Id. (dir.), Historia virtual. ¿Qué hubiera pasado si...? (pp. 11-86). Madrid: Taurus (orig. 1997).

Ferlazzo, L. (2011). The Best Resources For Teaching "What If?" History Lessons. http://larryferlazzo.edublogs.org/2012/05/19/the-best-resources-forteaching-what-if-history-lessons/

Frutos, J. I. de (2016). Juegos de simulación en el aula: una práctica que fomenta el pensamiento histórico. Tesis Doctoral (Facultad de Ciencias de la Educación - Universidad de Málaga). Málaga: Publicaciones y Divulgación Científica. Universidad de Málaga. https://riuma.uma.es/xmlui/handle/10630/12617

Fuster, C. (2018). Niveles de desarrollo de pensamiento histórico y narrativo en alumnos de 2o Bachillerato: un modelo conceptual y metodológico. En J. Monteagudo-Fernández, A. Escribano-Miralles y C. J. Gómez-Carrasco (eds.), Educación histórica y competencias transversales: narrativas, TIC y competencia lingüística (pp. 77-87). Murcia: Editum. Ediciones de la Universidad de Murcia. https://publicaciones.um.es/publicaciones/public/obras/ficha. seam?numero $=2648 \&$ edicion $=1$ 
Gibson, C. A. (2004). Learning Greek History in the Ancient Classroom: the Evidence of the Treatises on Progymnasmata. Classical Philology, 99, pp. 103-129. https://doi.org/10.1086/423858

Goldberg, T. y Savenije, G. M. (2018). Teaching Controversial Historical Issues. En S. A. Metzger y L. McA. Harris (eds.), The Wiley International Handbook of History Teaching and Learning (pp. 503-526). Nueva York: Wiley-Blackwell. https://doi. org/10.1002/9781119100812.ch19

Hailat, S., Eyadat, Y. y Zaid, Kh. (2018). The Effect of Using a Virtual History Strategy on the Development of Historical Thinking Skills for Undergraduate Classroom Teachers. The New Educational Review, 51(1), pp. 115-124. https://doi. org/10.15804/tner.2018.51.1.09

Helgason, P. (2010). Critical Thinking and the Textbook in History: an Odd Couple? En p. Helgason y S. Lässig (eds.), Opening the Mind or Drawing Boundaries? History Texts in Nordic Schools (pp. 163-184). Gotinga: V\&R unipress. Recuperado el 29 de marzo de 2021, de http://www.gei.de/fileadmin/gei.de/pdf/publikationen/ Schriftenreihe/fulltext/SRfulltext122.pdf

Howorth, M. (2015). Teaching Primary History. Londres - Nueva York: Bloomsbury.

Huijgen, T. y Holthuis, P. (2014). Towards bad history? A call for the use of counterfactual historical reasoning in history education. Historical Encounters: A journal of historical consciousness, historical cultures, and history education, 1(1), pp. 103-110. http://hej.hermes-history.net/index.php/HEJ/article/ view/36

Jensen, B. E. (2005). Counterfactual History and its Educational Potential. En P. Kemp (ed.), History in Education: Proceedings from the Conference History in Education (Danish University of Education, 24-25 March 2004) (pp. 151158). Copenhague: Danmarks Pædagogiske Universitets Forlag. http:// bernardericjensen.dk/wp-content/uploads/2012/01/counterfactual-history. pdf

Jiménez Alcázar, J. F. (2018). 'La historia no fue asi': reflexiones sobre el fenómeno de la historia contrafáctica en los videojuegos históricos. CLIO. History and History Teaching, 44. http://clio.rediris.es/n44/articulos/ monografico2018/07MonJimenez.pdf 
Jiménez Palacios, R.y Cuenca López, J. M.a (2015). El uso didáctico de los videojuegos. Concepciones e ideas de futuros docentes de ciencias sociales. CLIO. History and History Teaching, 41. Recuperado el 29 de marzo de 2021, de http://clio. rediris.es/n41/articulos/JimenezCuenca2015.pdf

Johanson, L. B. (2015). The Norwegian Curriculum in History and Historical Thinking: A case study of three lower secondary schools. Acta Didactica Norge, 9(1), pp. 1-24. https://doi.org/10.5617/adno.1301

Justvik, N. M. (2012). Tradisjonalisme og faktaorientering blant historielærere? Utvelgelsesprosesser for læreverk i historie i videregående skole: en pilotunders $\varnothing$ kelse [¿Tradicionalismo y orientación fáctica entre los profesores de historia? Procesos de selección de materiales didácticos de historia en la educación secundaria superior: un estudio piloto]. Acta Didactica Norge, 6(1), pp. 1-19. https://doi.org/10.5617/adno.1083

Justvik, N. M. (2014). Lærebokas dominerende posisjon i historieundervisningen - bare for elevenes skyld? [La posición dominante del libro de texto en la enseñanza de la historia: ¿solo por el bien de los estudiantes?]. Acta Didactica Norge, 8(1), pp. 1-20. https://doi.org/10.5617/adno.1098

Kiefer, H. C. y Kiefer, A. D. (1935-1936). Just suppose... New Comics, 1-4 (diciembre de 1935 - marzo/abril de 1936). Recuperado el 29 de marzo de 2021, de: http:// readallcomics.com/category/adventure-comics/

Kiefer, H. C. y Kiefer, A. D. (1936). Imagine that... More Fun Comics, 10 (mayo de 1936). https://comicbookplus.com/?dlid=64670

Kiefer, H. C. y Kiefer, A. D. (1936-1937). Just suppose... More Fun Comics, 11-25 (julio de 1936 - octubre de 1937). https://comicbookplus.com/?cid=736

Kitson, A., Husbands, Ch. y Steward, S. (2011). Teaching and Learning History 11-18. Understanding the Past. Maidenhead: McGraw-Hill.

Knutsen, K. (2017). Historiekompetanse for det digitale demokratiet. Undervisningsnettstedet NDLA $i$ et dramatistisk perspektiv [Competencia histórica para la democracia digital. El sitio web de educación NDLA en una perspectiva dramática]. En P. Brunbech, K. Knutsen y J. A. Poulsen (eds.), Historie - didaktik, dannelse og bevidsthed. Rapporter til det 29. Nordiske Historikermøde (vol. 1, pp. 114-137). Aalborg: Aalborg Universitetsforlag. https://www.cgs.aau.dk/digitalAssets/314/314795_konferencerapport-bd- 
1--nordisk-historikermoede-2017-.pdf?iframe=true \& width=1079.2\&heig ht $=485.6$

Kunnskapsdepartementet (2016). Meld. St. 28 (2015-2016). Fag - Fordypning - Forståelse. En fornyelse av Kunnskapsløftet [Informe al Storting 28 (20152016). Asignaturas - Especialización - Comprensión. Una renovación de Promoción del Conocimiento]. https://www.regjeringen.no/no/dokumenter/ meld.-st.-28-20152016/id2483955/

Kvande, L. y Naastad, N. $\left(2020^{2}\right)$. Hva skal vi med historie? Historiedidaktikk i teori og praksis [¿Qué vamos a hacer con la historia? Didáctica de la historia en la teoría y en la práctica]. Oslo: Universitetsforlaget (orig. 2013).

Lavold, A. (2016). "Like we have a choice". En studie av historisk narrativ i dataspill ["Like we have a choice». Un estudio de la narrativa histórica en los juegos de ordenador]. Masteroppgave i historie - femårig lektorutdanning (Institutt for historiske studier. Det humanistiske fakultet - Norges teknisknaturvitenskapelige universitet). https://ntnuopen.ntnu.no/ntnu-xmlui/ handle/11250/2431377

Lee, P. J. (1984). Historical Imagination. En A. K. Dickinson, P. J. Lee y P. J. Rogers (eds.), Learning History (pp. 85-116). Londres: Heinemann Educational Books.

Lévesque, S. (2013). Enseigner la pensée historique. Vancouver: The Critical Thinking Consortium.

Lieberoth, A. (2015). April 9th 1940, the Nazis are Coming: A Correlational Study of History Game's Mixed Effects on Knowledge, Attitudes and Thinking Skills. En R. Munkvold y L. Kolås (eds.), 9th European Conference on Games Based Learning 2015 (ECGBL 2015) (pp. 294-302). Reading: Academic Conferences and Publishing International Limited. http://milunesco.unaoc.org/wp-content/ uploads/2015/10/ECGBL2015-Proceedings-embedded.pdf

López Garzón, J. C. (2012). Didáctica para alumnos con altas capacidades. Madrid: Síntesis.

Lund, E. (2012). Historiebevissthetsbegrepet i engelsk historiedidaktikk teoriutvikling og didaktisk konkretisering $\mathrm{i}$ en ny læreplan [El concepto de conciencia histórica en la didáctica de la historia inglesa: desarrollo de la teoría y concretización didáctica en un nuevo plan de estudios]. En P. Eliasson, K. G. Hammarlund, E. Lund y C. T. Nielsen (eds.), Historiedidaktik i Norden 9. Del 
1: Historiemedvetande - historiebruk (pp. 96-116). Malmö: Malmö högskola

- Högskolan i Halmstad. http://hh.diva-portal.org/smash/get/diva2:515559/ FULLTEXT01.pdf

Maar, A. (2014). Possible Uses of Counterfactual Thought Experiments in History. Principia, 18(1), pp. 87-113. https://doi.org/10.5007/1808-1711.2014v18n1p87

Manum, K. M. (2016). "Kunne jeg ha handlet annerledes?". Betydninger av kontrafaktisk tenkning i en pedagogisk kontekst [«¿Podría haber actuado de manera diferente?». Significados del pensamiento contrafáctico en un contexto pedagógico]. Masteroppgave i pedagogikk, allmenn studieretning (Pedagogisk forskningsinstitutt. Det utdanningsvitenskapelige fakultet - Universitetet $\mathrm{i}$ Oslo). https://www.duo.uio.no/handle/10852/53906

Miralles Martínez, P., Molina Puche, S. y Ortuño Molina, J. (2011). La importancia de la historiografía en la enseñanza de la historia. Granada: Grupo Editorial Universitario.

Moesgaard, H. (2011). Skolens 1814. Fremstillinger av 1814 i norske lærebøker 19452010 [1814 de la escuela. Presentaciones de 1814 en los libros de texto noruegos 1945-2010]. Masteroppgave i historie (Institutt for arkeologi, konservering og historie - Universitetet i Oslo). https://www.duo.uio.no/handle/10852/23329

Moreno, A. C. (2020). What if? La historia alternativa como herramienta educativa. Íber. Didáctica de las Ciencias Sociales, Geografía e Historia, 99, pp. 60-65.

Moum, T. (2020, 7 de junio). Alle tiders historie og fagfornyelsen [Historia de todas las épocas y renovación profesional]. Fagsnakk fra Cappelen Damm. https:// www.fagsnakk.no/historie/alle-tiders-historie-og-fagfornyelsen/

Navey, M.-A. (2019). What do we want students to do when they are studying historical consequences? An exploratory case study based on a series of lessons taught to a Year Seven History class on the Black Death. Journal of Trainee Teacher Educational Research, 10, pp. 1-42. https://jotter.educ.cam.ac.uk/ volume10/01-042-naveyma/

Paulssen, Ch. (2011). Historiebevissthet: Erfaringsnært, men teorifjernt. En undersøkelse av undervisningsorienteringen til et utvalg historielærere $i$ videregående skoler i Sør-Trøndelag [Conciencia histórica: cercana a la experiencia, pero lejos de la teoría. Una encuesta sobre la orientación docente de una selección de profesores de historia en las escuelas secundarias superiores 
en Sør-Trøndelag]. Masteroppgave i samfunnsfagsdidaktikk (Fakultet for samfunnsvitenskap og teknologiledelse - Norges teknisk- naturvitenskapelige universitet). https://ntnuopen.ntnu.no/ntnu-xmlui/handle/11250/270276

Pelegrín Campo, J. (2010). La historia alternativa como herramienta didáctica: una revisión historiográfica. CLIO. History and History Teaching, 36. http://clio. rediris.es/n36/articulos/pelegrin.pdf

Pelegrín Campo, J. (2013). Entre la realidad y la ficción. Posibilidades didácticas del falso documental en el aula de Historia. En J. J. Díaz Matarranz, A. Santisteban y Á. Cascajero (eds.), XXIV Simposio Internacional de Didáctica de las Ciencias Sociales. Medios de comunicación y pensamiento crítico. Nuevas formas de interacción social (Guadalajara, 2013) (pp. 491-498). Alcalá de Henares: Universidad de Alcalá de Henares. http://didactica-ciencias-sociales.org/wpcontent/uploads/2013/11/publiGDJA.pdf

Pelegrín Campo, J. (2014a). Historia contrafáctica y didáctica de la Historia. Íber. Didáctica de las Ciencias Sociales, Geografía e Historia, 78, pp. 53-60.

Pelegrín Campo, J. (2014b). La historia contrafáctica en los manuales de Historia de ESO y Bachillerato: modelos y propuestas. Ensayos. Revista de la Facultad de Educación de Albacete, 29(1), pp. 115-130. https://revista.uclm.es/index.php/ ensayos/article/download/501/453

Pelegrín Campo, J. (2018). Otra Segunda Guerra Mundial: cómic, ucronía y didáctica de la Historia. En J. Gracia Lana y A. Asión Suñer (eds.), Nuevas visiones sobre el cómic. Un enfoque interdisciplinar. Actas del I Congreso Internacional de Estudios Interdisciplinares sobre Cómic (Zaragoza, 4-6 de abril de 2017) (pp. 301-307). Zaragoza: Prensas de la Universidad de Zaragoza.

Percival, J. (2020). Understanding \& Teaching Primary History. Londres: Sage Publising.

Radio Nouspace (2013-). Stroke of Fate. Programa radiofónico estadounidense integrado por trece episodios emitidos entre el 4 de octubre y el 27 de diciembre de 1953 por la National Broadcasting Company (NBC). http://www. radionouspace.net/programs/strokeoffate/

Reinsve, C. (2018). Kritisk tenkning i samfunnsfag. Samfunnsfaglæreres forståelse av kritisk tenkning og hvordan de fremmer det hos elever i samfunnsfag [Pensamiento crítico en ciencias sociales. La comprensión de los profesores 
de ciencias sociales acerca del pensamiento crítico y cómo lo promueven en los estudiantes de ciencias sociales.]. Masteroppgave i skolerettet utdanningsvitenskap med fordypning i samfunnsfag (Fakultetet for lærerutdanning og internasjonale studier - OsloMet - storbyuniversitetet). https://oda.oslomet.no/handle/10642/6241

Roberts, S. L. (2011). Using Counterfactual History to Enhance Students' Historical Understanding. The Social Studies, 102(3), pp. 117-123. https://doi.org/10.108 0/00377996.2010.525547

Rodwell, G. (2013). Whose History? Engaging History Students through Historical Fiction. Adelaida: The University of Adelaide Press. https://doi.org/10.20851/ whose-history

Rodwell, G. (2019). Using fiction to develop higher-order historical understanding. En T. Allender, A. Clark y R. Parkes (eds.), Historical Thinking for History Teachers. A new approach to engaging students and developing historical consciousness (pp. 194-207). Londres: Allen \& Unwin. https://doi.org/10.4324/978100311597717

Rosenfeld, G. D. (2005). The World Hitler Never Made: Alternate History and the Memory of Nazism. Cambridge - Nueva York: Cambridge University Press.

Santisteban Fernández, A. (2010). La formación de competencias de pensamiento histórico. Clío \& Asociados, 14, pp. 34-56. https://doi.org/10.14409/cya. v1i14.1674

Schei Medrano, S. (2020). Historiefaget mellom fag og folk. En studie av innspillsrundene til læreplanen for historie $i$ videregående opplæring [La disciplina de historia entre asignaturas y personas. Un estudio de las rondas de aportaciones al plan de estudios de historia en la educación secundaria superior]. Mastergradsoppgave $\mathrm{i}$ historie ved lektorutdanninga (Fakultet for humaniora, samfunnsvitenskap og lærerutdanning. Institutt for historie og religionsvitenskap - UiT Norges arktiske universitet). https://hdl. handle. net/10037/18780

Seixas, P. y Morton, T. (2013). The Big Six Historical Thinking Concepts. Toronto: Nelson Education.

Simone, G. C. De (2018). Counterfactuals, Possible Worlds and Smartphones. En I. A. Sánchez, P. Isaías y L. Rodrigues (eds.), 14th International Conference Mobile 
Learning 2018 (Lisbon, Portugal, 14-16 April 2018) (pp. 201-204). Lisboa: International Association for Development of the Information Society. http:// files.eric.ed.gov/fulltext/ED590369.pdf

Skjæveland, Y. (2016). Teaching Cultural Heritage in Culturally Diverse Early Childhood Centres in Norway. International Journal of Historical Learning, Teaching and Research, 13(2), pp. 82-92. https://doi.org/10.18546/HERJ.13.2.10

Skjæveland, Y. (2017). Learning history in early childhood. Teaching methods and children's understanding. Contemporary Issues in Early Childhood, 18(1), pp. 8-22. https://doi.org/10.1177/1463949117692262

Skram, H. F. (2008). For første gang i skolen: Kontrafaktisk historie [Por primera vez en la escuela: historia contrafáctica]. Fortid, 2, pp. 52-54. https://www.fortid. no/tidsskrift/fortid_0802.pdf

Skram, H. F. (2011). Historiefaget i Kunnskapsløftet: Dyktiggjøre og bevisstgjøre [La asignatura de historia en Promoción del Conocimiento: empoderamiento y concienciación]. Acta Didactica Norge, 5(1), pp. 1-29. http://doi.org/10.5617/ adno.1063

Smith, N. (2010). The History Teacher's Handbook. Londres - Nueva York: Bloomsbury.

Solhaug, T., Borge, J. A. O. y Grut, G. (2020). Social science education (samfunnsfag) in Norway. A country report. Journal of Social Science Education, 19(1), pp. 4768. https://doi.org/10.4119/jsse-1748

Statistisk sentralbyra (2021). Utdanning [Educación]. https://www.ssb.no/en/ utdanning

Stensletten, A. (2017). Digital historiesimulering i undervisning. Muligheter og begrensninger [Simulación histórica digital en la docencia. Oportunidades y limitaciones]. Masteroppgave i historie ved lektorutdanninga (Institutt for historie og religionsvitenskap - UiT Norges arktiske universitet). https://munin. uit.no/handle/10037/11540

Sætre, P. J. (2021). Kontinuitet eller brot? Geografi i grunnskulen etter 'fagfornyinga' 2020 [¿Continuidad o ruptura? La geografía en la educación primaria después de la «renovación de asignaturas» 2020]. Norsk Geografisk Tidsskrift - Norwegian 
Journal of Geography, 75(2), pp. 114-121. https://doi.org/10.1080/00291951. 2021.1884595

Sørensen, $\varnothing$. (2014, 28 de julio). Hva om Tyskland hadde vunnet? [¿Y si hubiera vencido Alemania?]. NRK Ytring. https://www.nrk.no/ytring/hva-om-tysklandhadde-vunnet_-1.11824878

Tarr, R. (2016). A History Teaching Toolbox. Practical strategies for the secondary classroom. Scotts Valley: Createspace.

Thomas, E. (2017). 100 Ideas for Secondary Teachers. Outstanding History Lessons. Londres - Nueva York: Bloomsbury.

Thue, F. W. (2019). Den historiske allmenndannelse. Historiefaget i høyere/ videregående skole, 1869-2019 [La educación general histórica. La asignatura de historia en la escuela superior / secundaria superior, 1869-2019]. Historisk Tidsskrift, 98(2), pp. 167-190. https://doi.org/10.18261/issn.1504-2944-201902-04

Vassbotn, Ch. (2014). Historiske kilder i klasserommet - å skrape overflata. En undersøkelse om lærernes mål med bruk av kilder og kildekritikk i historieundervisningen [Fuentes históricas en el aula: para arañar la superficie. Una encuesta sobre los objetivos de los profesores con el uso de fuentes y la crítica de fuentes en la enseñanza de la historia]. Mastergradsoppgave i historie (Institutt for historie og religionsvitenskap - UiT Norges arktiske universitet). de https://munin.uit.no/handle/10037/6411

Wendell, J. (2020). Qualifying counterfactuals: Students' use of counterfactuals for evaluating historical explanations. History Education Research Journal, 17(1), pp. 50-66. https://doi.org/10.18546/HERJ.17.1.05

Woodcock, J. (2011). Causal explanation. En I. Davies (ed.), Debates in History Teaching (pp. 124-136). Londres - Nueva York: Routledge.

Worth, P. (2012). Competition and counterfactuals without confusion: Year 10 play a game about the fall of the Tsarist empire to improve their causal reasoning. Teaching History, 149, pp. 28-35.

Wright-Maley, C., Lee, J. K. y Friedman, A. (2018). Digital Simulations and Games in History Education. En S. A. Metzger y L. McA. Harris (eds.), The Wiley 
International Handbook of History Teaching and Learning (pp. 603-629). Nueva York: Wiley-Blackwell. https://doi.org/10.1002/9781119100812.ch23

Ytreb $\varnothing$, A. О. (2019). Utformingen av de nye kjerneelementene for historiefaget $i$ videregående opplæring. En historiedidaktisk studie [El diseño de los nuevos elementos centrales de la asignatura de historia en la educación secundaria Superior. Un estudio sobre didáctica de la historia]. Masteroppgave i historie ved lektorutdanninga (Fakultetet for humaniora, samfunnsvitenskap og lærerutdanning - UiT Norges arktiske universitet). https://munin.uit.no/ handle/10037/15411 